\title{
Histological and Gene Expression Analyses in Banana Reveals the Pathogenic Differences between Races 1 and 4 of Banana Fusarium Wilt Pathogen
}

\author{
Honghong Dong, ${ }^{1}$ Huiyun Fan, ${ }^{1}$ Zhaoxi Lei, ${ }^{1}$ Chao Wu, ${ }^{1,2}$ Dengbo Zhou, ${ }^{3}$ and Huaping $\mathrm{Li}^{1, \dagger}$ \\ ${ }^{1}$ State Key Laboratory of Conservation and Utilization of Subtropical Agro-bioresources, Guangdong Province Key Laboratory of Microbial \\ Signals and Disease Control, College of Agriculture, South China Agricultural University, Guangzhou 510642, China \\ ${ }^{2}$ Guangzhou Institute of Forestry and Landscape Architecture, Guangzhou, Guangdong 510405, China \\ ${ }^{3}$ Institute of Tropical Bioscience and Biotechnology, China Academy of Tropical Agricultural Sciences, Haikou, Hainan, China \\ Accepted for publication 27 February 2019.
}

\begin{abstract}
Fusarium oxysporum f. sp. cubense, the causative agent of Panama disease, is classified into three races: Foc1, Foc2, and Foc4. However, the histological characteristics, the accumulation of fusaric acid (FA), and resistant gene expression in banana infected with different races remain unclear. In this study, we compared the infection processes, FA contents, and gene expression levels in a Cavendish banana cultivar (Musa AAA Brazilian) inoculated with Foc 1 and Foc4. Results showed that Foc4 can rapidly extend from the roots to the leaves, whereas Foc 1 expands slowly from the roots to the rhizomes but cannot expand further upward. In addition, the colonization of plants by Foc4 was significantly higher compared with Foc1, as was the content of FA in those infected plant tissues. We observed that a large amount of starch granules was produced in the rhizomes and the number of starch granules was significantly higher after infection with Foc 1 than after infection with Foc4. We further found that starch has an important inhibitory effect on the phytotoxicity
\end{abstract}

ABSTRACT induced by FA, thus leading to more resistance to the pathogens in the plants with high amounts of starch accumulation than in those with a low amount of starch accumulation. Moreover, the expression levels of 10 defense-related genes were analyzed and the results showed that the induction levels of those genes were higher after infection with Foc1 than after infection with Foc4. These results suggest that the observed differences in the invasion of host tissues and FA accumulation, and the number of starch granules and expression of defense-related genes, may contribute to a difference in virulence between the two races and the resulting difference in host resistance response, respectively.

Keywords: analytical and theoretical plant pathology, banana, fusaric acid, Fusarium oxysporum f. sp. cubense, gene expression, histological observation, mycology, pathogenic differences, starch granules.
Banana (Musa spp. AAA) is a principal fruit crop in tropical and subtropical regions worldwide. However, banana production is threatened by Fusarium wilt, a highly destructive fungal disease (Stover 1962). Fusarium wilt of banana, also called Panama disease, is caused by the soilborne fungus Fusarium oxysporum f. sp. cubense (Ploetz 2006). The disease was first reported in Australia in 1876 , and it caused significant damage in export plantations in the Western tropics before 1960 . The pathogen invades banana roots or root injury sites, colonizes and occludes the vascular tissues, and then induces a reddish-brown discoloration of the rhizomes and pseudostems, leading to leaf collapse and, finally, the death of banana plants (Stover 1962). In addition, F. oxysporum f. sp. cubense can survive in the soil for decades (Ploetz 1994). Soils infected with $F$. oxysporum f. sp. cubense cannot be replanted with susceptible cultivars.

F. oxysporum f. sp. cubense can be classified into three physiological races, according to their degree of pathogenicity against different host cultivars (Dita et al. 2010; Ploetz 2006). Race 1 (Foc 1) attacks the cultivar Gros Michel (Musa spp., AAA) and has caused epidemics in the past century. Race 2 (Foc2) affects Bluggoe

†Corresponding author: H. Li; huaping@scau.edu.cn

Funding: The work was supported by the earmarked fund for Modern Agroindustry Technology Research System in China (CARS-32-09).

*The $\boldsymbol{e}$-Xtra logo stands for "electronic extra" and indicates that five supplementary figures and two supplementary tables are published online.

The author(s) declare no conflict of interest.

C 2019 The American Phytopathological Society
(Musa spp., ABB), as well as other cooking banana cultivars, and race 4 (Foc4) causes diseases to Cavendish banana cultivars (Musa spp., AAA) and all other banana cultivars susceptible to Foc 1 and Foc2 (Ploetz 2006). Fusarium wilt caused by Foc 1 destroyed the Gros Michel banana and was responsible for significant yield losses earlier in the last century (Ploetz et al. 1990; Stover 1962). Eventually, Foc1-susceptible Gros Michel banana was replaced by resistant Cavendish cultivars. However, Foc4, which can attack Cavendish cultivars, was reported in Taiwan in 1967 (Ploetz 2006). To date, the present production of banana is largely restricted by Fusarium wilt caused by Foc 4 because most banana plants are Cavendish cultivars (Dita et al. 2010; Ploetz 2006; Stover and Malo 1972).

Currently, various strategies have been employed to control this destructive pathogen; however, the use of resistant cultivars is the most acceptable and economical to deal with Fusarium wilt (Michielse and Rep 2009). Although researchers have been striving to improve the resistance of banana, commercially available varieties to resistant Fusarium wilt disease are limited thus far. Investigation of the interaction between banana and $F$. oxysporum $\mathrm{f}$. sp. cubense will provide new insights into the mechanism by which the host plant responds to the disease and may lead to the discovery of efficient ways to control banana Fusarium wilt disease.

Most previous studies focused on the development of resistant Cavendish cultivars (Getha and Vikineswary 2002; Li et al. 2015; Nel et al. 2006), molecular detection (B. Li et al. 2013; Peng et al. 2014; Zhang et al. 2013), biological control by using beneficial microorganisms that colonize the banana rhizosphere (Fu et al. 2017; Naik et al. 2008), pathogenesis-related fungal genes (FraserSmith et al. 2014; Sutherland et al. 2013), resistance-related genes 
of plants (Peraza-Echeverria et al. 2008), and disease control (Akila et al. 2011; Zacky and Ting 2015). Studies on the infection process of $F$. oxysporum f. sp. cubense mainly focused on susceptible banana varieties inoculated with Foc1, Foc4 (Beckman et al. 1961; Li et al. 2011; Waite 1977; Wardlaw 1931), or both (Guo et al. 2015 ). These studies suggest that $F$. oxysporum f. sp. cubense can penetrate the susceptible roots of banana cultivars, expand through the vascular organization, and, finally, cause wilt in banana plants. Xiao et al. (2013) suggested that effective retardation of the Foc4 hyphal movement from the rhizomes to the pseudostems may delay banana wilt disease. $\mathrm{Li}$ et al. (2017) indicated that direct root penetration and rhizome vascular colonization are the key steps of successful $F$. oxysporum f. sp. cubense infection. However, insufficient information is available about the differences in the infection processes between Foc 1 and Foc4, especially how both races expand from the roots to the upper parts of banana plants and the different effects of these races on the histological characteristics and defense-related gene expression patterns in each part of banana plants.

In addition, fusaric acid (FA), a nonspecific toxin produced by Fusarium spp., is known for its high phytotoxicity (Gapillout et al.1996). Although several studies on the mode of action of FA have been conducted (Niehaus et al. 2014; Stipanovic et al. 2011), the role of FA in pathogenicity differences between Foc 1 and Foc4 to banana is poorly understood.

In the current investigation, two green fluorescent protein (GFP)tagged isolates of Foc 1 and Foc4 were developed and utilized to study the infection process on a Cavendish cultivar, Brazilian, susceptible to Foc 4 but resistant to Foc 1 , by using confocal laserscanning microscopy (LSM). The root, rhizome, pseudostem, leaf sheath, and leaf tissues of this cultivar at different time points after inoculation with Foc 1 and Foc4 were investigated. Histological differences, FA contents, and defense-related gene expression patterns in the different tissues of Brazilian plants infected by Foc 1 and Foc 4 were compared to understand the pathogenicity differences between races Foc 1 and Foc4.

\section{MATERIALS AND METHODS}

Plant materials. Cavendish banana cultivar Brazilian (Musa spp. AAA) was used in this study. Each plantlet with five leaves and approximately $15 \mathrm{~cm}$ in height was transplanted into a plastic pot (10 cm in diameter) containing sterile coconut chop medium. All banana plantlets were kept in a constant-temperature incubator at $28^{\circ} \mathrm{C}$ with a photoperiod of $16 \mathrm{~h}$ of light and $8 \mathrm{~h}$ of darkness and a light intensity of 5,000 Lux.

Fusarium strains and GFP-tagged modification. Strains of Foc1 FJZ3 (VCG 01221) and tropical Foc4 XJZ2 (VCG 01216) were modified with the GFP gene by using the sGFP expression cassette from a vector gGFP (Lorang et al. 2001) provided by Professor Amir Sharon (Tel Aviv University, Israel). Agrobacterium tumefaciens strain AGL-1 and binary vector $\mathrm{pBHt} 1$ were provided by the South China Agricultural University fungal laboratory. Plasmid construction and A. tumefaciens-mediated transformation (ATMT) were described by Mullins et al. (2001). The growth characteristics and pathogenicity of $G F P$-tagged $F$. oxysporum f. sp. cubense were examined using the procedures described by Li et al. (2007).

Plant inoculation. The GFP-tagged isolates of Foc 1 and Foc 4 were used to observe the infection process. Before the research, we performed inoculation experiments with $F$. oxysporum f. sp. cubense and confirmed that Brazilian was susceptible to Foc4 and resistant to Foc 1. Plants with healthy root systems were selected for inoculation, and plant inoculation was performed as described by Van Den Berg et al. (2007), with some modifications. Plant roots were soaked in $800 \mathrm{ml}$ of GFP-tagged Foc 4 or GFP-tagged Foc 1 spore suspension at $10^{6} \mathrm{conidia} / \mathrm{ml}$ for $30 \mathrm{~min}$, then planted back to the pots. The mock-inoculated control plants were treated with sterile distilled water (mock control). Afterward, the infected plantlet tissues were harvested at 13 different time points: 24, 48, $72,96,120,144,168,216,264,312,360,480$, and $720 \mathrm{~h}$ after inoculation. In total, 10 plants were prepared for each time point, and each experiment was repeated thrice.

Microscopic observation. The roots, rhizomes, pseudostems, leaf sheaths, and leaves of the plants inoculated with either Foc 1 or Foc 4 were examined for infection process and colonization at 13 different time points after inoculation. For microscopic observation, banana tissues were washed in sterile distilled water, then cut into thin sections along the vertical and longitudinal axes by hand sectioning. Then, the tissue sections were placed on a microscope slide, submerged in a water droplet, and covered with a glass cover slip. Microscopic observation was carried out under a confocal laser-scanning microscope (LSM 780; Zeiss) equipped with filter blocks with spectral properties matching the fluorescence of GFP (excitation wavelength at $488 \mathrm{~nm}$ and emission wavelength at $520 \mathrm{~nm}$ ) and the autofluorescence of plant tissues (excitation wavelength at $543 \mathrm{~nm}$ and emission wavelength at $590 \mathrm{~nm}$ ). Five plants were prepared for each time point, and each experiment was repeated thrice.

Starch granule staining observation. The starch granule staining observation was carried out according to the method described by Hovenkamp-Hermelink et al. (1987), with some minor modification. Briefly, $1 \mathrm{~g}$ of iodine was dissolved in $100 \mathrm{ml}$ of $5 \%$ potassium iodide (vol/wt) to prepare a solution of $1 \%$ iodinepotassium iodide $\left(1 \% \mathrm{I}_{2}-\mathrm{KI}\right)$. The rhizomes were sectioned, immersed in $1 \% \mathrm{I}_{2}-\mathrm{KI}$ solution for $1 \mathrm{~min}$, then washed with sterile distilled water and observed by a light transmission microscopy (UC103i; UOP).

Real-time polymerase chain reaction amplification and quantification for $F$. oxysporum f. sp. cubense abundance. The roots, rhizomes, pseudostems, leaf sheaths, and leaves of plants inoculated with either Foc 1 or Foc 4 were collected at 13 different time points after inoculation, immediately frozen in liquid nitrogen, then stored in a freezer at $-80^{\circ} \mathrm{C}$ until use. Genomic DNA was extracted using the Magen HiPure Plant DNA Mini Kit, in accordance with the manufacturer's instructions. To detect Foc1 and Foc 4 abundance, we used two specific primer sets, Foc-1/Foc-2 for Foc 1 (M.-H. Li et al. 2012) and W1805F/W1805R for Foc4 (Lin et al. 2009). The primer sequences are listed in Supplementary Table S1. Standard curves were prepared according to the method described by Fan et al. (2017). A 242-bp fragment was produced by polymerase chain reaction (PCR) from Foc4 genomic DNA (gDNA) and a 354-bp fragment from Foc1 gDNA. The F. oxysporum f. sp. cubense fragments were gel purified, cloned into $\mathrm{pMD}^{\mathrm{TM}} 18$-T vector (Takara), and sequenced. After plasmid purification, the plasmid DNA concentration was quantified using spectrophotometer (Nanodrop). The copy number of standard plasmids was calculated according to plasmid (2,692 bp) plus insert lengths (242 or $354 \mathrm{bp}$ ) and assuming a molecular mass of $660 \mathrm{Da}$ for a base pair. Standard DNA stock solutions of plasmid at $10^{9}$ copies $\mu 1^{-1}$ were prepared. For standard curve plotting and meltingcurve analysis of real-time PCR amplification, 10-fold serial dilutions of the target DNA, ranging from $10^{7}$ to $10^{2}$ copies/ reaction, were performed and yielded linear and reliable results (efficiency, 90 to $110 \%$; correlation coefficient, $R^{2}>0.99$ ).

Finally, a real-time PCR assay was conducted to detect the abundance of $F$. oxysporum f. sp. cubense in $F$. oxysporum $\mathrm{f}$. sp. cubense-infected banana. When testing DNA samples, banana ribosomal protein $\mathrm{S} 2$ gene (RPS2) was employed as the reference gene to make samples to be normalized (Chen et al. 2011). Ten plants were prepared for each time point, and each experiment was repeated thrice.

Determination of starch contents in banana rhizomes. Fresh rhizome tissues of plants inoculated with either Foc 1 or Foc 4 were collected at $0,168,216,264,312,360,480$, and $720 \mathrm{~h}$ after inoculation. Afterward, the samples were immediately frozen in 
liquid nitrogen, ground to powder, and weighed. The starch contents in $0.1 \mathrm{~g}$ of the rhizome powder were determined using a plant starch content assay kit (Comin Biotechnology Co., Ltd.) in accordance with the manufacturer's instructions. Ten plants were prepared for each time point, and the experiment was repeated thrice.

FA production of $F$. oxysporum f. sp. cubense in vitro culture. FA production of $F$. oxysporum $\mathrm{f}$. sp. cubense in vitro culture was performed according to the method described by Morpurgo et al. (1994), with some modification. Briefly, nine mycelial discs of Foc 1 or Foc4, cultured for 7 days on potato dextrose agar (PDA) plates, were inoculated into $300 \mathrm{ml}$ of the modified sterilized Richard culture medium $\left(10 \mathrm{~g}\right.$ of $\mathrm{KNO}_{3}, 5 \mathrm{~g}$ of $\mathrm{KH}_{2} \mathrm{PO}_{4}, 2.5 \mathrm{~g}$ of $\mathrm{MgSO}_{4} \cdot 7 \mathrm{H}_{2} \mathrm{O}, 0.02 \mathrm{~g}$ of $\mathrm{Fe}_{2}\left(\mathrm{SO}_{4}\right)_{3}, 50 \mathrm{~g}$ of sucrose, and $0.1 \mathrm{~g}$ of $\mathrm{ZnSO}_{4} \cdot 7 \mathrm{H}_{2} \mathrm{O}$ ), and incubated for 9 days at $30^{\circ} \mathrm{C}$ and a rotation speed of $140 \mathrm{rpm}$ with the continuous illumination of a light intensity of 5,000 Lux. The crude culture solution was sterilized at $121^{\circ} \mathrm{C}$ for $18 \mathrm{~min}$, treated by ultrasonication for $10 \mathrm{~min}$ (Ruisheng Instrument \& Meter Co., Ltd.), then filtered with double layers of gauze. The filtrate was centrifuged at $6,000 \mathrm{rpm}$ at normal temperature for $30 \mathrm{~min}$, and the supernatant was concentrated under reduced pressure at $45^{\circ} \mathrm{C}$ to $1 / 10$ of the original volume. After centrifugation at 5,000 rpm for $20 \mathrm{~min}$, the supernatant was filtered through a sterile filter paper, and the filtrate was stored at $4^{\circ} \mathrm{C}$ for FA extraction.

FA extraction and determination assay. FA was extracted according to the method described by Chakrabarti and Basu Chaudhary (1980) and Curir et al. (2000), with some modification. Briefly, banana roots, rhizomes, and pseudostems at 168, 360, and $480 \mathrm{~h}$ postinoculation with either Foc 1 or Foc 4 were weighed $(50 \mathrm{~g})$ and homogenized in a homogenizer with $80 \mathrm{ml}$ of double-distilled $\mathrm{H}_{2} \mathrm{O}$. An equal volume of ethyl acetate was added and the mixture was mixed, then placed in a $28^{\circ} \mathrm{C}$ constant-temperature shaker at $170 \mathrm{rpm}$ overnight. The mixture was allowed to stand for $20 \mathrm{~min}$ to allow the ethyl acetate and water phases to separate. Then, the upper ethyl acetate fraction was removed and added to a round-bottom flask for evaporation at $50^{\circ} \mathrm{C}$ using a rotary evaporator. The residue was dissolved by adding $10 \mathrm{ml}$ of ethanol, and the precipitate was discarded by centrifugation. The supernatant was steamed to dryness at $50^{\circ} \mathrm{C}$ in a desiccator under vacuum condition. The dried sample was dissolved by adding $10 \mathrm{ml}$ of methanol to prepare a sample solution.

FA contents were determined by the method of ultraviolet absorption using a Multiscan GO high-quality UV/VIS fullwavelength reader (Thermo Fisher Scientific) at $268 \mathrm{~nm}$. A calibration curve was made with pure FA (Sigma) dissolved in methanol.

Evaluation of starch effects in phytotoxicity induced with FA. Starch powder (Yuanye Biotechnology Co. Ltd.) was dissolved in sterile distilled water to prepare starch powder solutions of different concentrations $(2,6,10$, and $20 \mathrm{mg} / \mathrm{ml}$ [wt/vol]). These starch powder solutions were added to treatment solutions containing FA at $100 \mu \mathrm{g} / \mathrm{ml}$ (wt/vol), and then the roots of a banana plantlet were immersed in the different treatment solutions. All treated banana plantlets were kept in a constant-temperature incubator at $28^{\circ} \mathrm{C}$ with a photoperiod of $16 \mathrm{~h}$ of light and $8 \mathrm{~h}$ of darkness and a light intensity of 5,000 Lux. The plant symptoms at different time points were observed.

Quantitative real-time PCR analysis on the expressions of key genes in the starch synthetic pathway and defenserelated genes. We measured the expression levels of 6 key genes in the starch synthetic pathway (ADP-glucose pyrophosphorylase [AGPase], granule-binding starch synthase [GBSS], starch branching enzyme $[S B E]$, soluble starch synthases $[S S S]$, starch phosphorylase $[S P]$, and glucose-1-phosphate adenylyltransferase $[G P A])$ in banana roots and rhizomes at $168 \mathrm{~h}$ postinoculation with either Foc 1 or Foc4, and 10 defense-related genes (chitin elicitor receptor kinase 1 [CERK1], flagellin sensitive 2 [FLS2], serine/ threonine-protein kinase $[P B S 1]$, WRKY transcription factor 22
[WRKY22], pathogenesis-related proteins 1 [PR-1], chitinase, lipoxygenases $[L O X]$, jasmonate ZIM-domain protein [JAZ], glutathione-S-transferase [GST], and cellulose synthase) in banana roots, rhizomes, pseudostems, leaf sheaths, and leaves at 0,48 , and 168 h postinoculation with either Foc 1 or Foc4. Moreover, RPS2 was used as the reference gene (Chen et al. 2011). Total RNA was extracted using the TaKaRa MiniBEST Plant RNA Extraction Kit and treated with RNase free DNase I (TaKaRa), and cDNA was synthesized in $20 \mu \mathrm{l}$ of reaction system using the PrimeScript RT Master Mix Kit (TaKaRa). In addition, a no-RT control reaction was performed to ensure there did not have any DNA contamination. Reverse-transcription quantitative (RT-q)PCR was performed using the SYBR Premix Ex Taq Kit (TaKaRa) in accordance with the manufacturer's protocols. Relative changes in gene expression levels were calculated using the $2^{-\Delta \Delta C T}$ method, as described by Zhao et al. (2013). The primer sequences used for RT-qPCR analysis are listed in Supplementary Table S2. Ten plants were prepared for each time point, and the experiment was repeated thrice.

Statistical analysis. Data were analyzed with analysis of variance by using SPSS 16.0 for Windows (SPSS Inc.) and were graphed using Graph Pad Prism 7 (Graph Pad Software). All values were presented as mean values \pm standard deviations. Statistically significant differences were determined using Duncan's multiple range tests $(P<0.05)$ or Student's $t$ test $(*$ and $* *$ indicate $P<0.05$ and 0.01 , respectively).

\section{RESULTS}

GFP transformation and observation of GFP-tagged F. oxysporum f. sp. cubense. Two transformed isolates, Foc 1 and Foc4 expressing GFP, were obtained by ATMT. The expression of GFP in both transformed $F$. oxysporum f. sp. cubense isolates remained stable after successively transferring 40 generations on PDA medium with or without hygromycin B (data not shown). Biological experiments proved that neither the pathogenicity nor morphological features of the isolates were changed by the integration of the GFP gene to the genome of each $F$. oxysporum f. sp. cubense isolate by ATMT compared with the wild-type isolates (data not shown). Both GFP-tagged Foc 1 and Foc4 emitted bright fluorescence under green light excitation of $488 \mathrm{~nm}$ and were readily visible via confocal LSM (Fig. 1). Therefore, these isolates can be used for further research on the expansion and colonization of banana plants.

Histopathological observation on the different tissues of plants inoculated with GFP-tagged Foc1 and Foc4. To study the infection differences between Foc 1 and Foc4, we monitored the pathogen infection process using two GFP-expressing $F$. oxysporum f. sp. cubense isolates. The roots, rhizomes, pseudostems, leaf sheaths, and leaves of the Brazilian plants inoculated with the two
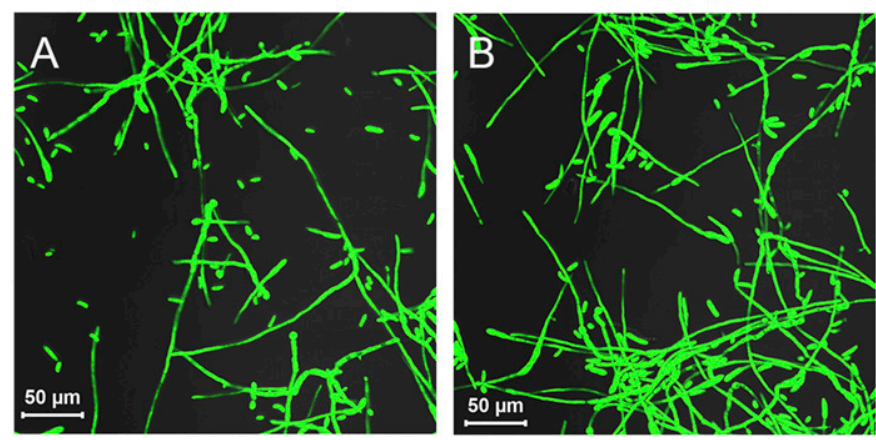

Fig. 1. Spores and mycelia morphological characteristics of green fluorescent protein-tagged Fusarium oxysporum f. sp. cubense causing Fusarium wilt of banana observed with a confocal microscopy. Scale bar $=50 \mu \mathrm{m}$. A, Race Foc 4 and $\mathbf{B}$, race Foc 1 . 
races of $G F P$-tagged $F$. oxysporum f. sp. cubense were sampled at different time points and observed via confocal LSM. The results were shown as follows. In addition, observations of the mockinoculated control are shown in Supplementary Figure S1.

Roots. Both GFP-tagged Foc1 and Foc4 could penetrate the vascular bundle tissues of the roots (Fig. 2). However, some differences in their infection process were observed. The conidia and hyphae of both Foc 1 and Foc 4 attached to the epidermal cells of the banana roots $24 \mathrm{~h}$ after infection (Fig. 2A, A1 and H, H1, respectively) and penetrated the cortex parenchyma of the roots at 48 h (Fig. 2B, B1 and I, I1, respectively). At 72 h, the hyphae of Foc 4 began to grow longitudinally along the intercellular spaces (Fig. 2J and J1) and, at $96 \mathrm{~h}$, the hyphae entered the xylem catheters (Fig. 2K and K1). At $360 \mathrm{~h}$, plant tissue slightly collapsed, and a massive amount of hyphae and spores of Foc 4 were observed on the vascular bundle tissues. However, the hyphae of Foc 1 were not observed in the xylem catheters of banana roots until $144 \mathrm{~h}$ after infection (Fig. $2 \mathrm{E}$ and $\mathrm{E} 1)$. Moreover, the amount of colonization was obviously limited from 48 to $216 \mathrm{~h}$ after infection. These results indicate that

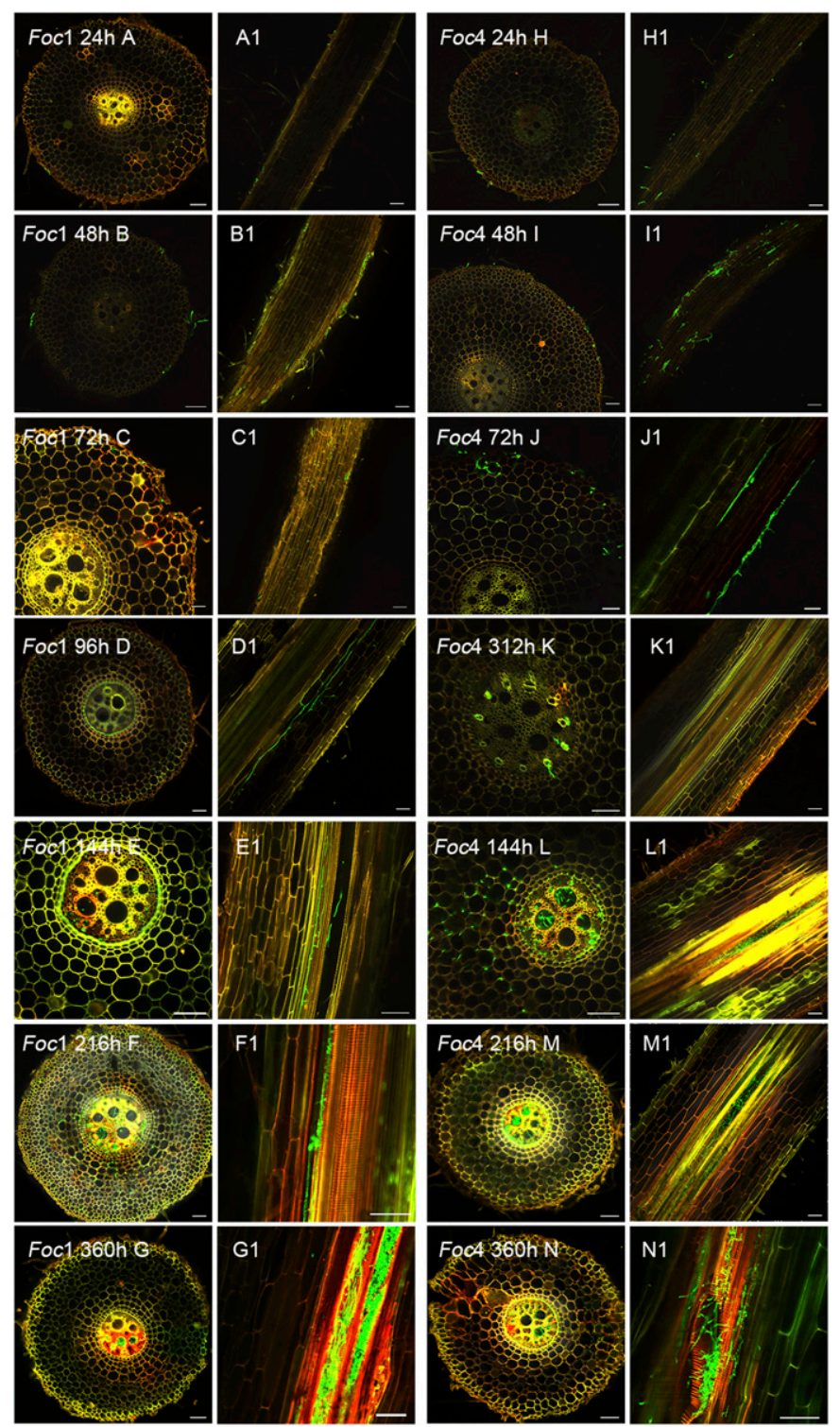

Fig. 2. Expansion and colonization in the roots of banana variety Brazilian (Musa spp. AAA) infected with either green fluorescent protein-tagged isolates Foc 1 or Foc 4 of Fusarium oxysporum f. sp. cubense at different time points $(24,48,72,96,144,216$, and $360 \mathrm{~h})$ after inoculation. A to $\mathbf{G}$, Infected by Foc 1 . $\mathbf{H}$ to $\mathbf{N}$, Infected by Foc 4 . A to $\mathrm{G}$ and $\mathrm{H}$ to $\mathrm{N}=$ transverse section, and $\mathrm{A} 1$ to $\mathrm{G} 1$ and $\mathrm{H} 1$ to $\mathrm{N} 1=$ longitudinal section. Scale bar $=100 \mu \mathrm{m}$. the expansion of Foc 4 is apparently faster than that of Foc 1 , and the amount of Foc4 colonization is distinctly higher than that of Foc 1 colonization at the same time points in the infected roots.

Rhizomes. Banana rhizomes showed slightly brownish discoloration $168 \mathrm{~h}$ after inoculation with Foc4 (Supplementary Fig. S2). However, no symptom was found after inoculation with Foc1 and
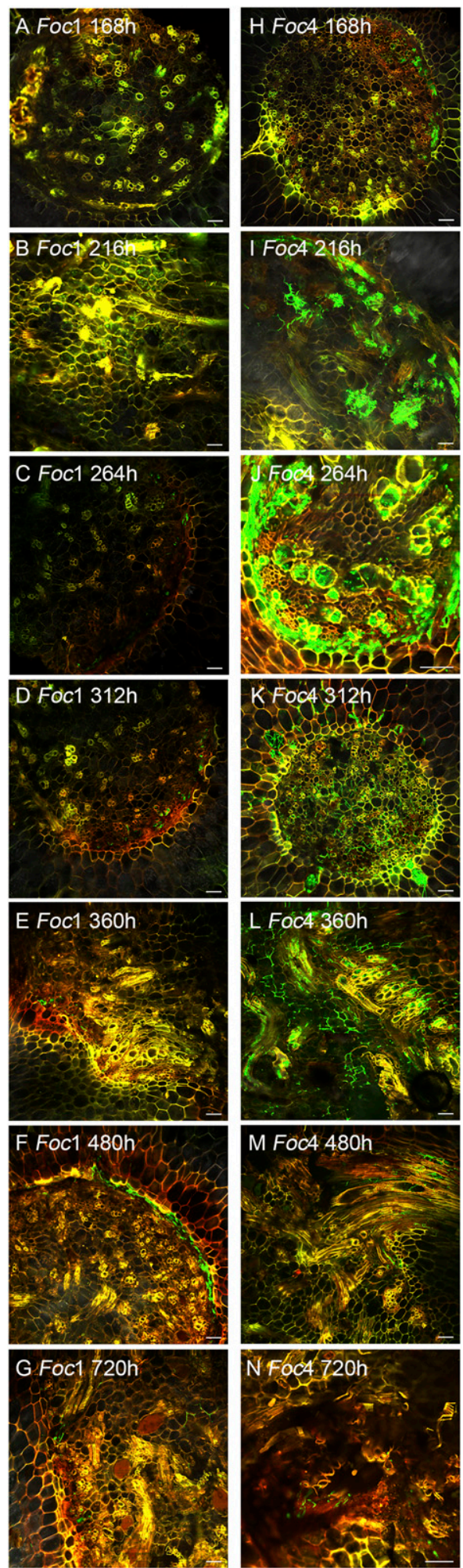

Fig. 3. Expansion and colonization in the rhizomes of banana variety Brazilian (Musa spp. AAA) infected with either green fluorescent protein-tagged isolates Foc 1 or Foc 4 of Fusarium oxysporum f. sp. cubense at different time points $(168,216,264,312,360,480$, and $720 \mathrm{~h})$ after inoculation. $\mathbf{A}$ to $\mathbf{G}$, Infected by Foc 1 . H to N, Infected by Foc 4 . Scale bar $=100 \mu \mathrm{m}$. 
the mock control. Therefore, we selected the rhizome tissues each at $168,216,264,312,360,480$, and $720 \mathrm{~h}$ postinoculation for observation. Results showed that the hyphae of Foc 4 were observed in the rhizomes168 $\mathrm{h}$ after root inoculation (Fig. 3H). Subsequently, Foc4 expanded its hyphal network by growing in the intercellular spaces along the junctions of the rhizome epidermal cells at
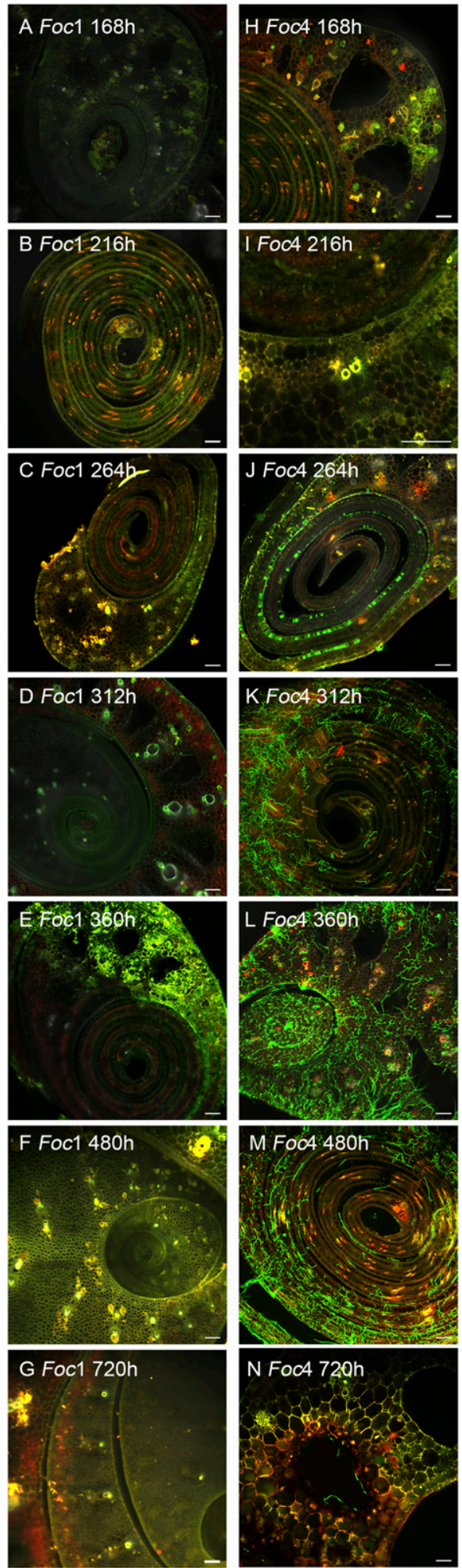

Fig. 4. Expansion and colonization in the pseudostems of banana variety Brazilian (Musa spp. AAA) infected with either green fluorescent proteintagged isolates Foc 1 or Foc 4 of Fusarium oxysporum f. sp. cubense at different time points $(168,216,264,312,360,480$, and $720 \mathrm{~h})$ after inoculation. $\mathbf{A}$ to $\mathbf{G}$, Infected by Foc1. H to N, Infected by Foc 4 . Scale bar $=100 \mu \mathrm{m}$.
312 h (Fig. 3K). Between 360 and 720 h, the rhizome tissues became infected with soft rot, and the plantlet gradually withered and eventually died. At this stage, vigorous hyphae were still observed in the rotten tissues (Fig. 3L to N). However, Foc 1 was not observed in the rhizome until $264 \mathrm{~h}$ (Fig. 3C). At the end of the observation, although some hyphae of Foc 1 could be observed, the amount of Foc 1 colonization was much lower than that of Foc 4 colonization. Moreover, the tissue structures of the rhizomes might be intact during the different time points after infection with Foc 1 . Thus, no evident disease symptom was observed in the rhizomes.

Pseudostems. To further understand the expansion and colonization of pathogens in banana plants, we examined the status of F. oxysporum f. sp. cubense in the pseudostems from 168 to $720 \mathrm{~h}$ after root inoculation. Small amounts of Foc 4 hyphae were observed
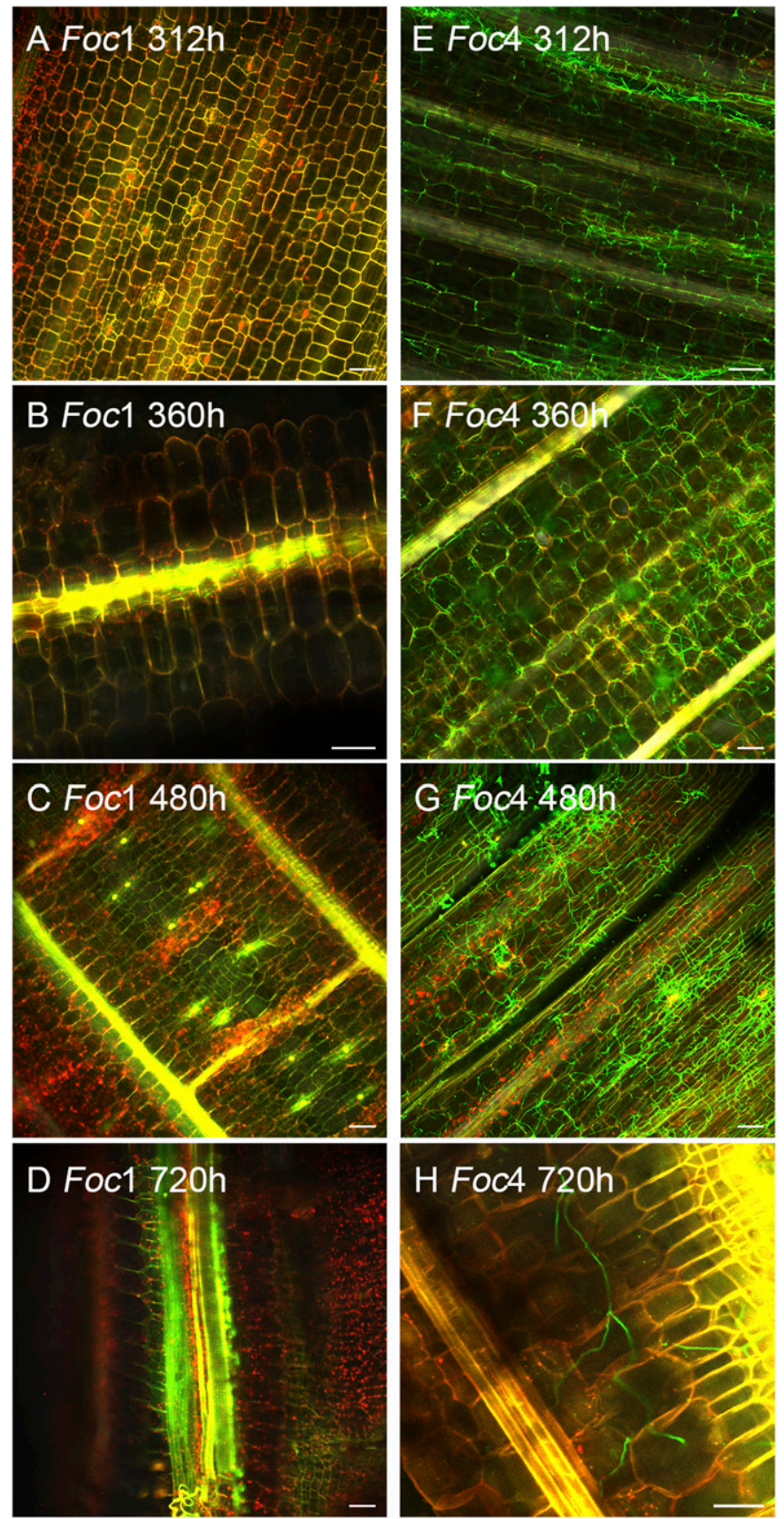

Fig. 5. Expansion and colonization in the leaf sheaths of banana variety Brazilian (Musa spp. AAA) infected with either green fluorescent proteintagged isolates Foc 1 or Foc 4 of Fusarium oxysporum f. sp. cubense at different time points $(312,360,480$, and $720 \mathrm{~h})$ after inoculation. $\mathbf{A}$ to $\mathbf{D}$, Infected by Foc1. E to H, Infected by Foc 4 . Scale bar $=100 \mu \mathrm{m}$. 
in the vascular tissues of the pseudostems at 168 and $216 \mathrm{~h}$ (Fig. $4 \mathrm{H}$ and I) and then expanded to the interval tissues between the parenchyma and aerenchyma of the pseudostems at $264 \mathrm{~h}$ (Fig. 4J). At subsequent time points, Foc 4 hyphae covered large sections of the pseudostems (Fig. $4 \mathrm{~K}$ to $\mathrm{M}$ ), and the plant tissues gradually collapsed (Fig. 4N). However, Foc 1 hyphae were not observed in the pseudostems at all time points from 168 to $720 \mathrm{~h}$ after the infection (Fig. 4A to G). These results indicate that Foc4, not Foc1, can expand from the rhizomes to the pseudostems after pathogen infection from the roots.

Leaf sheaths. At $312 \mathrm{~h}$ after Foc 4 infection from the roots, the plant leaves showed yellowing, and the leaf sheaths exhibited brown patches near the rhizome site. Meanwhile, the plants looked relatively healthy at $312 \mathrm{~h}$ after Foc 1 infection (Supplementary Fig. S3). Also, at this stage, the leaf sheaths were observed. Foc 4 hyphae were distributed to whole tissues of the leaf sheaths (Fig. 5E). From 312 to $480 \mathrm{~h}$, increasing amounts of hyphae in the tissues were found (Fig. 5F and G). At $720 \mathrm{~h}$, the tissues collapsed, and few hyphae were still observed (Fig. 5H). However, as expected, no Foc 1 hyphae were found at each time point (Fig. 5A to D).

Leaves. The leaves of infected plants became bright yellow after Foc4 inoculation at $312 \mathrm{~h}$. However, the plants were normal after Foc 1 inoculation. The leaves of plants infected with Foc 1 or Foc 4 were observed from 360 to $720 \mathrm{~h}$ after inoculation. The results showed that no fungal material was observed at any time point after
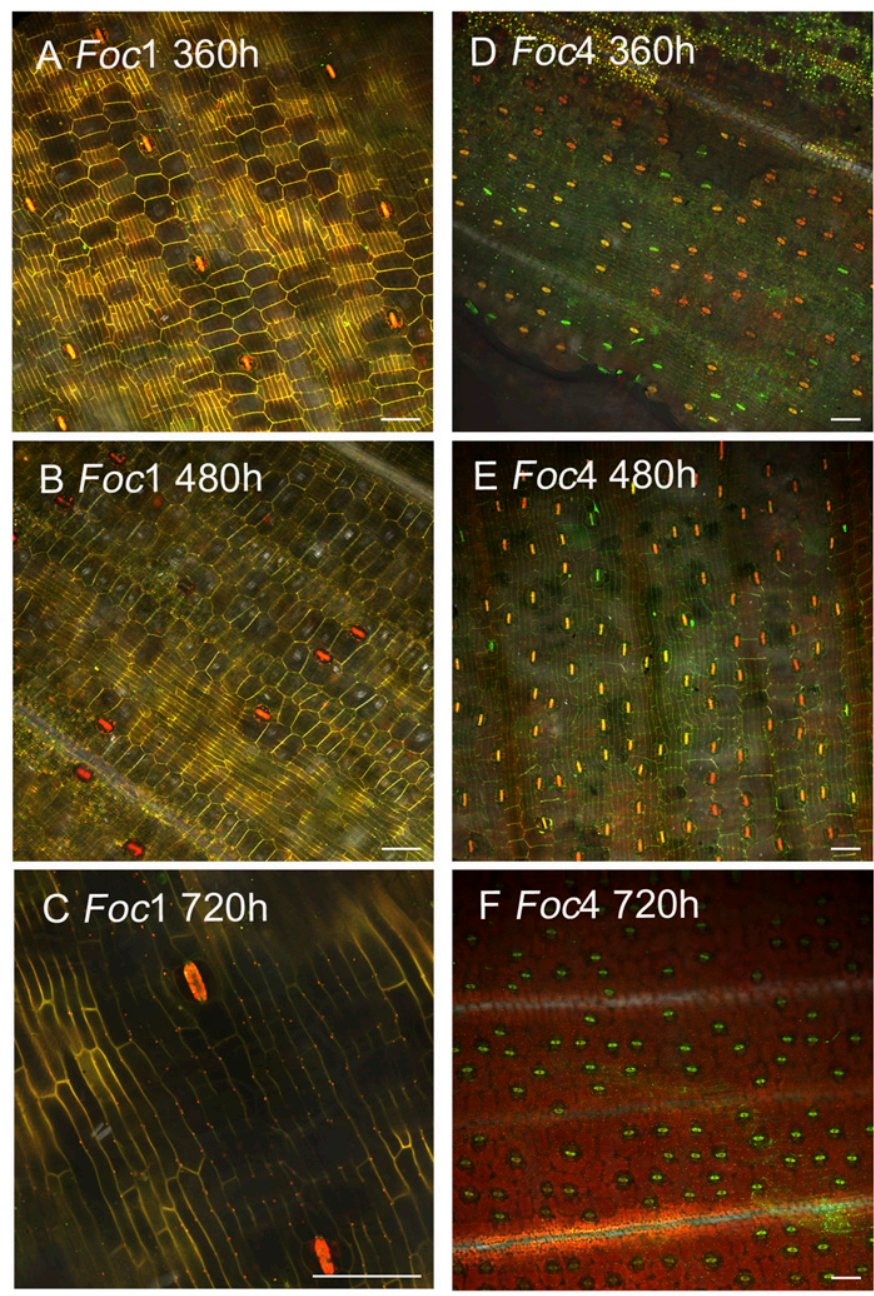

Fig. 6. Expansion and colonization in the leaves of banana variety Brazilian (Musa spp. AAA) infected with either green fluorescent protein-tagged isolates Foc 1 or Foc 4 of Fusarium oxysporum f. sp. cubense at different time points $(360,480$, and $720 \mathrm{~h})$ after inoculation. A to C, Infected by Foc1. D to F, Infected by Foc4. Scale bar $=100 \mu \mathrm{m}$.
Foc 1 infection (Fig. 6A to C). In contrast, apparent fungal hyphae were found on the leaf stomata and on the guard cells of yellowing and wilted leaves 360 to $720 \mathrm{~h}$ after Foc4 infection (Fig. 6D to F). This result indicates that Foc4 hyphae can expand from the infected roots to the leaves.

Quantification of pathogen abundance in different parts of banana plant. Combining the results obtained from histopathological observations, we analyzed the pathogen abundance by RTqPCR in different parts of the plants at different time points after the roots were inoculated with $F$. oxysporum f. sp. cubense (Fig. 7). Our results showed that the abundance of Foc 4 was significantly higher than that of Foc 1 in banana roots and rhizomes at the same time points from 24 to $720 \mathrm{~h}$ (Fig. 7A and B). Moreover, Foc 1 in the pseudostems, leaf sheaths, and leaves was not detected at each time point from 168 to $720 \mathrm{~h}$. However, Foc4 was detected in the pseudostems at all time points from 168 to $720 \mathrm{~h}$, and the abundance gradually increased with time (Fig. 7C). Similarly, Foc 4 could be detected in the leaf sheaths at all time points from 168 to $720 \mathrm{~h}$ (Fig. 7D) and in the leaves from 360 to $720 \mathrm{~h}$ (Fig. 7E). However, the abundance of Foc4 first increased from 168 to $312 \mathrm{~h}$ and then slightly decreased at $360 \mathrm{~h}$ in the leaf sheaths (Fig. 7D). Meanwhile, Foc 4 was only detected in the leaves starting at $360 \mathrm{~h}$, and the abundance gradually increased from 360 to $720 \mathrm{~h}$ (Fig. 7E). These results are consistent with our histopathological observation.

Starch granule observation and determination of starch contents in rhizomes. Examination of the infection process of $G F P$-tagged $F$. oxysporum f. sp. cubense in banana rhizomes showed that the starch granules filled the rhizome cells at $168 \mathrm{~h}$ after inoculation. However, their size was similar and the number was significantly higher after infection with Foc1 (Fig. 8A and B) than after infection with Foc4 (Fig. 8C and D) and the mock control (Fig. $8 \mathrm{E}$ and $\mathrm{F}$ ). Moreover, at subsequent time points from 216 to $720 \mathrm{~h}$, the number of starch granules further increased after infection with Foc 1, thereby resulting in a higher number differences compared with infection with Foc4. To further confirm the abovementioned results, we stained the sliced rhizome tissues at $168 \mathrm{~h}$ after treatment with $1 \% \mathrm{I}_{2}$-KI and observed them under a light transmission microscope. The number of the starch granules remarkably increased in the tissues infected with Foc1 (Fig. 8G and H) compared with those infected with Foc 4 (Fig. 8I and J) and the mock control (Fig. 8K and L). In addition, similar results were observed at 216 to $720 \mathrm{~h}$ (data not shown).

To verify the abovementioned results, we determined the total starch contents in the rhizomes at different time points after inoculation with $F$. oxysporum f. sp. cubense. Results showed that the starch contents in the plants infected with Foc1 were significantly higher $(P<0.05)$ than those in the plants infected with Foc 4 at all time points. The starch contents gradually increased from 0 to $480 \mathrm{~h}$ and then slightly decreased at $720 \mathrm{~h}$ after inoculation with Foc1 (Fig. 9). By contrast, the starch contents remained constant and did not show statistically significant differences $(P<$ 0.05 ) from 0 to $720 \mathrm{~h}$ after the plants were inoculated with Foc 4 . The results were similar to those observed in the mock control. These results indicate that Foc 1 infection can significantly induce an increase in the starch granules in banana rhizomes.

Expression analysis of key genes in the starch synthetic pathway in rhizomes and roots. To explore the change in starch contents during the interaction between $F$. oxysporum $\mathrm{f}$. sp. cubense and plants, we selected six key genes related to the pathway of starch synthesis that were retrieved from our transcriptome data (Bai et al. 2013). These genes included AGPase, GBSS, SBE, SSS, $S P$, and GPA. The RNA expression levels of these key genes in the rhizomes were analyzed using RT-qPCR. Results showed that all of six genes were induced by $F$. oxysporum $\mathrm{f}$. sp. cubense inoculation, and the expression levels of these genes were significantly upregulated. Moreover, the levels of upregulation at all time points were much higher after infection with Foc 1 than after infection with Foc4 (Fig. 10). 
In addition, expression analysis of these six genes was carried out in banana roots at different time points after $F$. oxysporum $\mathrm{f}$. sp. cubense inoculation. Results showed that the induction patterns of six genes were significantly different between Foc 1 and Foc 4 (Supplementary Fig. S4). Moreover, the expression levels of these genes were considerably higher at most time points after infection with Foc1 than after infection with Foc4. These results further suggest that the starch content differences in the plant tissues infected with Foc1 and Foc4 are consistent with the expression levels of the starch synthesis-related genes.

Detection of FA contents in production in vitro culture and infected banana tissues. To further investigate the pathogenicity differences between Foc 1 and Foc4, first, a standard curve $(y=21.496 x+0.0882)$ was established by measuring the optical density at $268 \mathrm{~nm}$ values of different concentrations of pure FA, and the correlation coefficient was calculated to be 0.9954 (Fig. 11A). Then, the FA amounts were determined in F. oxysporum f. sp. cubense in vitro culture and infected banana tissues (roots, rhizomes, and pseudostems) at 168,360 , and $480 \mathrm{~h}$ after $F$. oxysporum f. sp. cubense inoculation. The results showed that the amounts of FA production in vitro culture were not significantly different between Foc 1 and Foc 4 (data not shown). However, the amounts of FA were significantly higher in the infected banana roots, rhizomes, and pseudostems at each of three time points after infection with Foc4 than after infection with Foc1 (Fig. 11B). A certain concentration of FA can lead to blight symptoms, and an overconcentration of FA from Foc 4 may be an important cause of the plant disease.

Evaluation of starch effects in phytotoxicity induced with FA. Before evaluating the effect of starch on the phytotoxicity induced with FA, an experiment of phytotoxicity induced with FA was performed. The Brazilian plant roots were immersed in different contents of FA $(0,50,100,200,300$, and $500 \mu \mathrm{g} / \mathrm{ml}$ [wt/vol]) and the results are shown in Supplementary Figure S5. As the contents of FA increased, the phytotoxicity gradually increased. When FA was used at $100 \mu \mathrm{g} / \mathrm{ml}$, the rhizomes became apparently brown at $96 \mathrm{~h}$ after treatment. Therefore, FA at $100 \mu \mathrm{g} / \mathrm{ml}$ was chosen to evaluate the effect of starch on phytotoxicity induced with FA, and the results are shown in Figure 12. Although the plants were treated in the solution containing only FA, the leaves and rhizomes of the plants began to wilt and become brown, respectively, at $48 \mathrm{~h}$ (Fig. 12H); then, whole plants died at $120 \mathrm{~h}$ (Fig. 12T). However, the plants were treated in the mixed solution containing FA and starch powder at $20 \mathrm{mg} / \mathrm{ml}$, leaf wilting at $120 \mathrm{~h}$ and rhizome browning at $48 \mathrm{~h}$ were apparently observed, and the plants still survived at $120 \mathrm{~h}$ (Fig. 12L to X). By analysis of different treatments, we conclude that the resistance of banana plants increases gradually against FA with the increasing of the starch powder contents in the treatment solutions. This suggests that starch has an important inhibitory effect on the phytotoxicity induced by FA.

Expression analysis of the defense-associated genes in banana plants. We selected 10 defense-related genes (namely, CERK1, FLS2, PBS1, WRKY22, PR-1, chitinase, LOX, JAZ, GST, and cellulose synthase) and then analyzed their expression levels in the roots, rhizomes, pseudostems, leaf sheaths, and leaves of the banana plants infected by both $F$. oxysporum $\mathrm{f}$. sp. cubense races after inoculation at 48 and $168 \mathrm{~h}$. All 10 genes were induced by infection with Foc1 and Foc4 (Fig. 13). However, the induction patterns were significantly different. For example, all genes except cellulose synthase were upregulated in the banana roots at $48 \mathrm{~h}$ after inoculation with Foc 1 (Fig. 13A). Moreover, eight genes, including CERK1, PBS, WRKY22, PR-1, chitinase, LOX, JAZ, and GST, were upregulated by infection with Foc1. However, these genes were downregulated or slightly changed at $48 \mathrm{~h}$ after infection with Foc4 (Fig. 13A). Statistical analysis indicated that the expression levels of four genes (WRKY22, PR-1, chitinase, and LOX) were
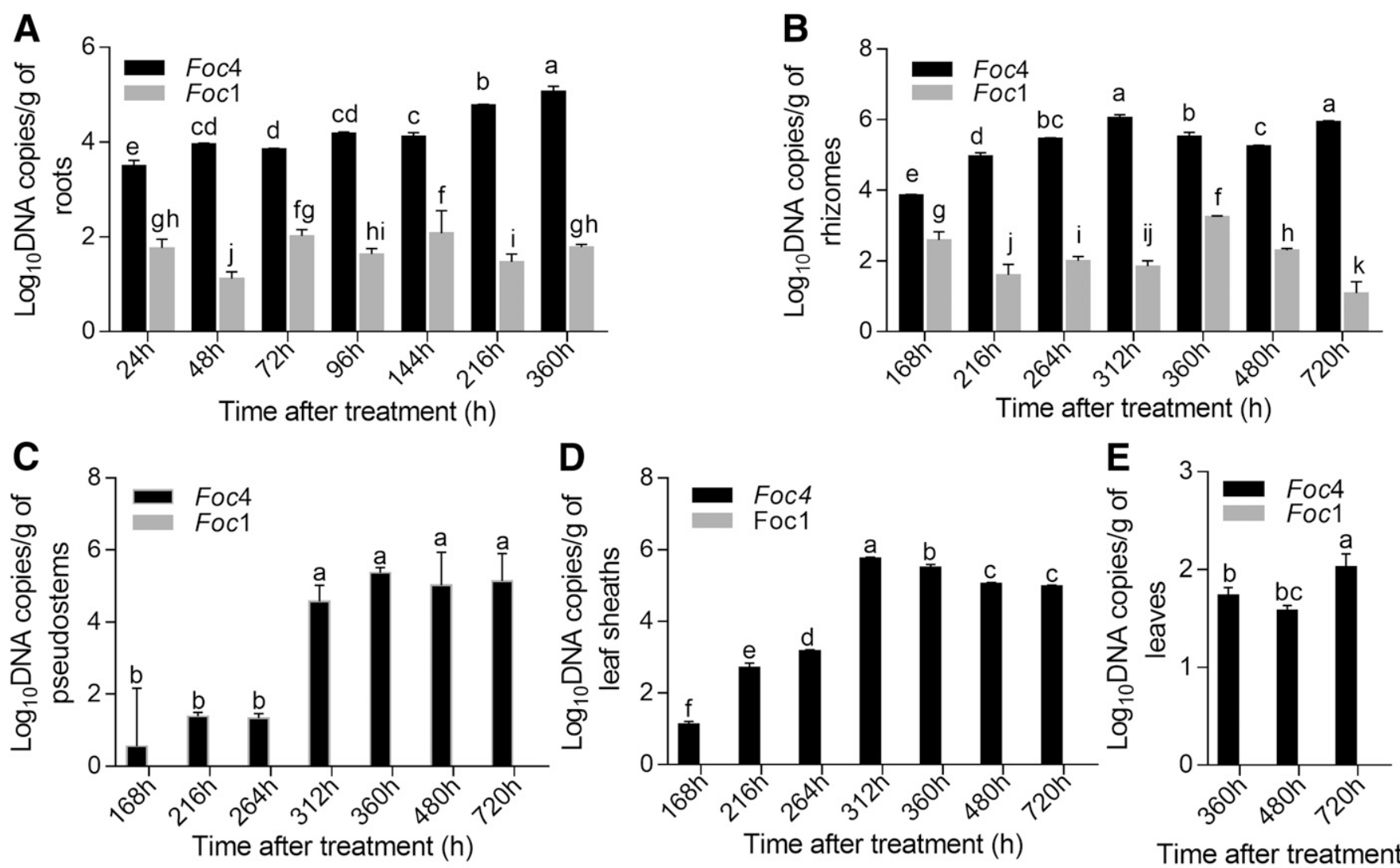

Time after treatment (h)

Fig. 7. Abundance of races Foc 1 and Foc4 of Fusarium oxysporum f. sp. cubense in different parts of banana (Musa spp. AAA) at different time points after $F$. oxysporum f. sp. cubense inoculation. A, Root; B, rhizome; C, pseudostem; D, leaf sheath; and $\mathbf{E}$, leaf. Data represent mean value of three independent replicates. Significant differences were determined according to Duncan's multiple range test at $P<0.05$. Error bars represent + standard deviation.

Vol. 109, No. 6, 2019 
significantly different $(P<0.05)$ in the banana roots infected with Foc 1 and Foc4 at 48 h (Fig. 13A).

At $168 \mathrm{~h}$ after inoculation, although the expression levels of these defense-related genes in the roots, rhizomes, pseudostems, leaf sheaths, and leaves showed different dynamic variations, the expression levels of these genes after infection with Foc 1 were generally higher than those after infection with Foc4 (Fig. 13B to F). Statistical analysis showed that the expression levels of different genes in different tissues of plants infected with Foc 1 and $F o c 4$ were significantly different. For example, five genes ( $F L S 2, P B S, L O X$, GST, and cellulose synthase) in the roots (Fig. 13B), three genes (CERK1, GST, and cellulose synthase) in the rhizomes (Fig. 13C), five genes (CERK1, WRKY 22, PR-1, chitinase, and LOX) in the pseudostems (Fig. 13D), nine genes (CERK1, FLS2, PBS, PR-1, chitinase, LOX, JAZ, GST, and cellulose synthase) in the leaf sheaths (Fig. 13E), and six genes (CERK1, FLS2, WRKY22, PR-1, JAZ, and cellulose synthase) in the leaves (Fig. 13F) showed significantly different expression levels $(P<0.05)$ after infection with $F o c 1$ and Foc 4. Based on these data, we conclude that the higher expression levels of these defense-related genes in the different parts of plants after infection with Foc 1 than after infection with Foc 4 may have contributed to the stronger resistance of banana variety Brazilian against Foc 1 than Foc4.

\section{DISCUSSION}

In the past, Foc 1 was responsible for the widespread epidemics of Fusarium wilt disease (Panama disease), which caused significant losses to banana production. Since then, Cavendish varieties have been the most widely used varieties in the majority of banana plantations because of their resistance to Foc1 (O'Donnell et al. 1998). However, the appearance of Foc 4 has posed a serious threat to the Cavendish banana varieties.

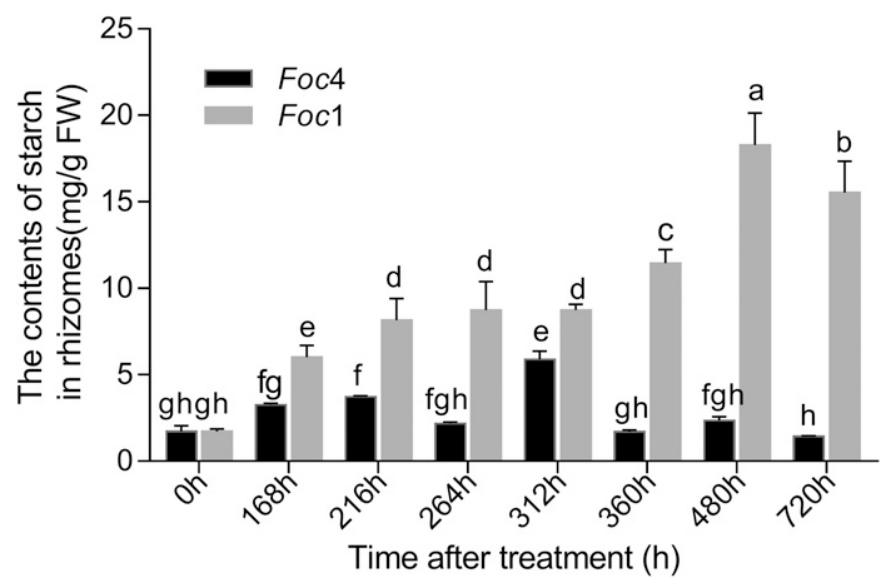

Fig. 9. Contents of starch in banana (Musa spp. AAA) rhizomes at different time points $(168,216,264,312,360,480$, and $720 \mathrm{~h})$ after infection by Fusarium oxysporum f. sp. cubense races Foc 1 and Foc4. Data represent an average of three biological replicates and were normalized to the mock control. Error bars are standard deviation (+SD). Values followed by the same letter are not significantly different according to Duncan's multiple range test at $P<0.05$.

\section{Confocal}
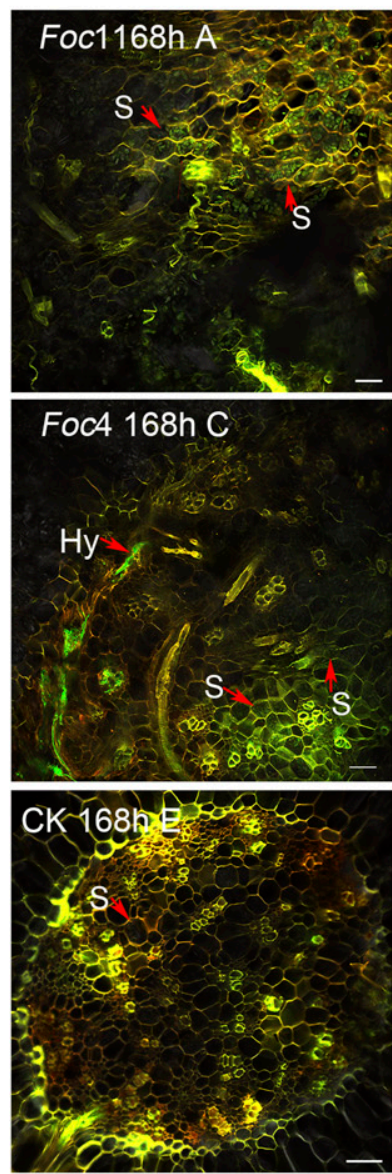
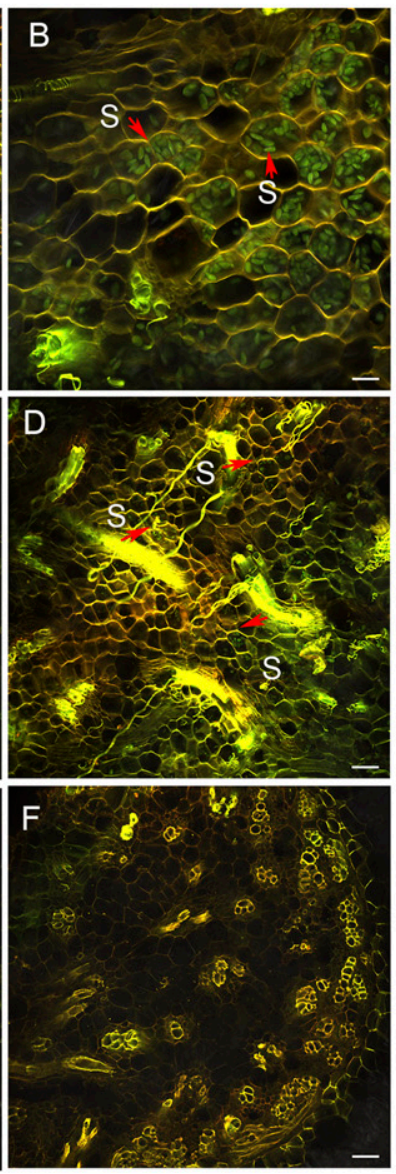

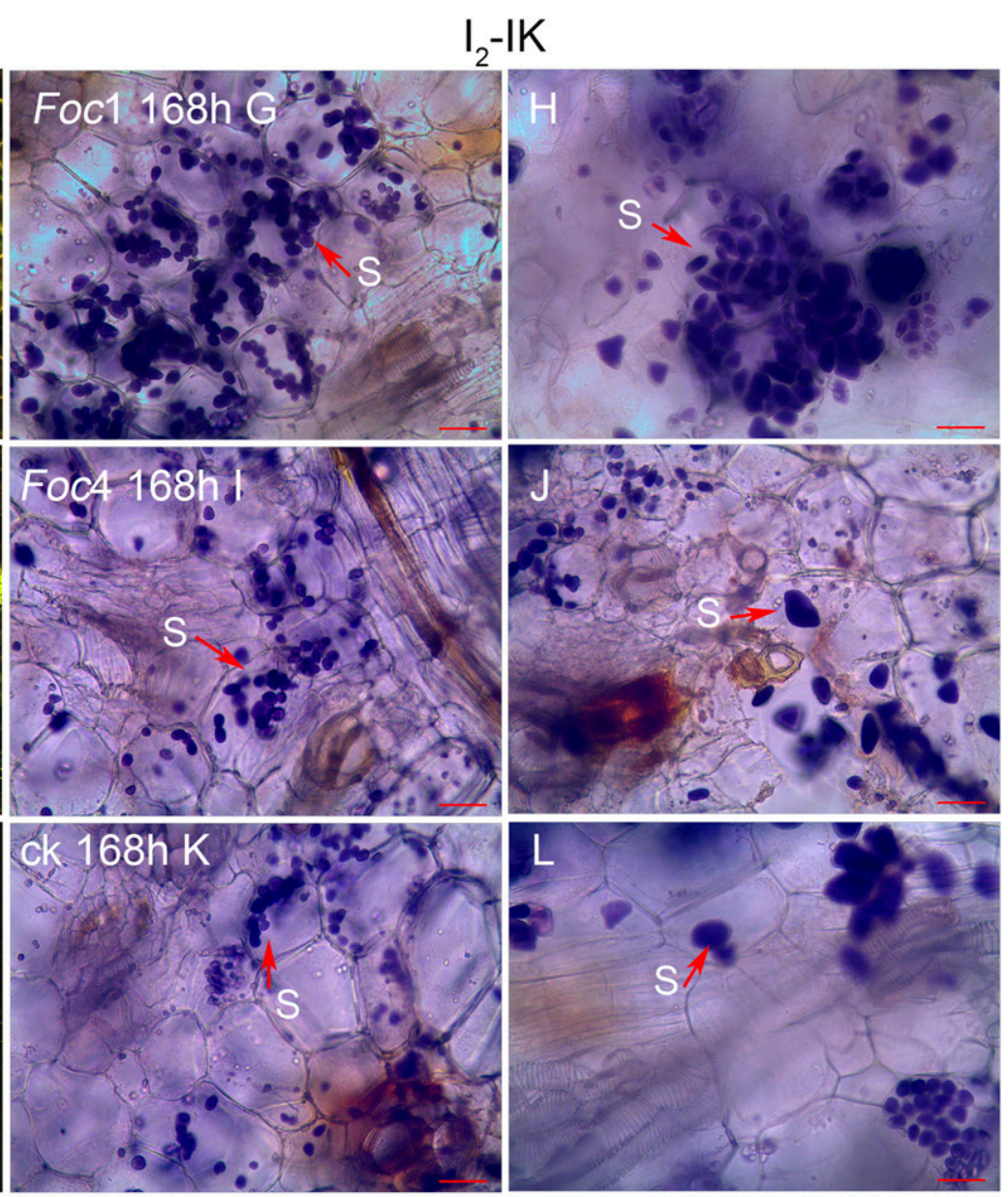

Fig. 8. Microscopic observation of starch granules in banana rhizomes at $168 \mathrm{~h}$ after Fusarium oxysporum f. sp. cubense and mock inoculation. Confocal A to F, Banana rhizomes were sectioned and observed with a confocal microscopy; iodine-potassium iodide $\left(\mathrm{I}_{2}-\mathrm{KI}\right) \mathbf{G}$ to $\mathbf{L}$, banana rhizomes were sectioned, stained with $1 \% \mathrm{I}_{2}-\mathrm{KI}$, and observed by light transmission microscopy. A, B, G, and $\mathrm{H}=$ Mock-inoculation control; C, D, I, and J = infected by Foc 1; and E, F, K, and $\mathrm{L}=$ infected by Foc 4 . Scale bars represent $100 \mu \mathrm{m}$ in A to $\mathrm{F}$ and $200 \mu \mathrm{m}$ in $\mathrm{G}$ to $\mathrm{L}$. S $=$ starch granules and Hy = hyphae. 
Currently, breakthroughs have been made in the study of the interaction between host plants and pathogens using GFP-tagged pathogens. GFP-transformed plant pathogens can be visualized in plant tissues without any manipulation of samples, thereby making the technology extremely useful in observing the pathogen infection process (Lorang et al. 2001). In the current study, to provide assistance in monitoring the $F$. oxysporum $\mathrm{f}$. sp. cubense infection process in banana, we successfully transformed the GFP gene into the isolates of both $F$. oxysporum $\mathrm{f}$. sp. cubense races by ATMT. Similar to the results obtained by previous studies (Freitag et al. 2001; Lorang et al. 2001; Visser et al. 2004), transformed
$G F P$-tagged $F$. oxysporum f. sp. cubense races were able to emit bright, uniform fluorescence. This result laid the foundation for follow-up experiments.

In this study, we used confocal LSM to observe the pathogen infection process of different parts of Brazilian plants at different time points after inoculation with GFP-tagged Foc 1 and Foc4. Our results indicated that both Foc 1 and Foc 4 could penetrate the epidermis of the roots and invade the xylem vessels. This finding was consistent with the results of previous studies (Li et al. 2011; C.-Q. Li et al. 2013; Guo et al. 2014, 2015). Li et al. (2017) pointed out that Foc4 could penetrate the roots from the wounds and
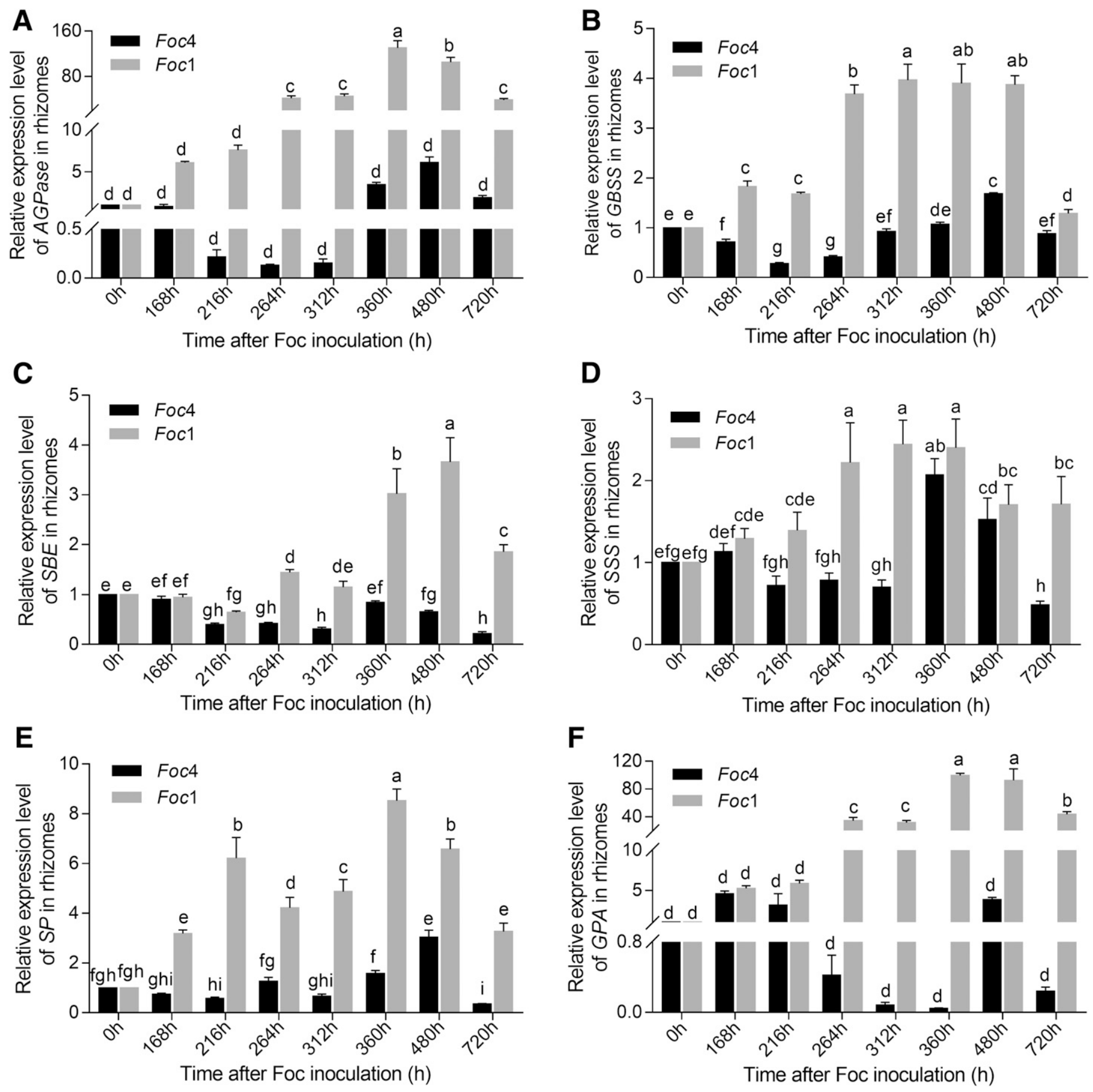

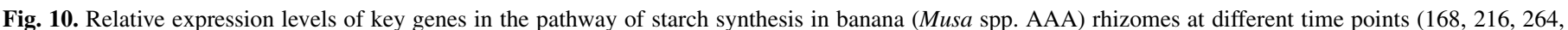

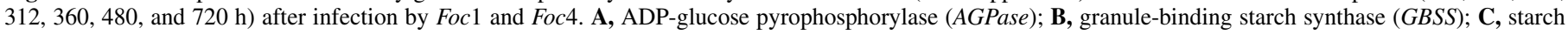

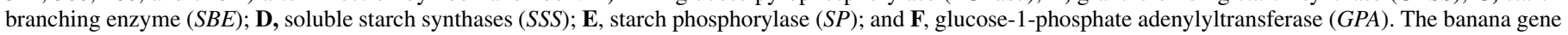

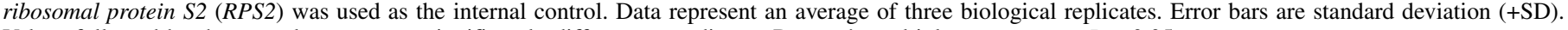
Values followed by the same letter are not significantly different according to Duncan's multiple range test at $P<0.05$. 
intercellular space of the epidermis whereas Foc 1 mainly penetrated the wounds. In the current research, we further observed that pathogens were more likely to invade the wounds and the lateral roots. In addition, Foc 1 required $144 \mathrm{~h}$ to expand into the xylem catheters after infection, whereas Foc 4 did so by 96 h. Furthermore, the fungal biomass of Foc 4 was significantly higher than that of Foc 1 at each time point from 24 to $360 \mathrm{~h}$ after infection. These results showed that the infection rates and the hyphae enrichment of the two F. oxysporum f. sp. cubense races significantly differed after invasion. Kuang et al. (2013) pointed out that the plants of banana cultivars with different resistance to $F$. oxysporum f. sp. cubense altered the cell structure when they were infected with $F$. oxysporum f. sp. cubense, and one of the alterations was that the spaces between vessel perforation plates of the plants became smaller in resistant varieties than in susceptible varieties. Thus, the migration of fungal mycelium through the vascular bundles in the resistant cultivars was somewhat inhibited, thereby minimizing the pathogen infection rate (Beckman et al. 1961). It also seemed that the activity of the pectin methylesterase (PME) induced by the infection with Foc 1 and Foc 4 was different, and the higher increase of PME activity induced by infection with Foc4 than infection with Foc 1 resulted in the direct damage of cell wall (Fan et al. 2017; Ma et al. 2013). Therefore, Foc 4 is more invasive than Foc 1 during the early stage of the infection process in Brazilian banana plants.

Most previous reports focused on banana root infection with F. oxysporum f. sp. cubense (Beckman et al. 1961; Guo et al. 2015; Li et al. 2011; Li et al. 2017; Wardlaw 1931; Xiao et al. 2013). In the present study, we systematically analyzed the differences of two races in the expansion and localization of the rhizomes, pseudostems, leaf sheaths, and leaves of Brazilian plants at different time points after inoculation. An interesting finding was that the expansion ranges of both $F$. oxysporum $\mathrm{f}$. sp. cubense races were remarkably different in these parts after $F$. oxysporum f. sp. cubense infection. Li et al. (2017) observed the presence of Foc 1 hyphae only in the roots but we observed the presence of Foc 1 in root and rhizome tissues after infection with Foc 1 . According to previous reports, the expansion range of Foc4 was mostly from root to rhizome (Li et al. 2017) or from root to rhizome and pseudostem (Xiao et al. 2013); however, no fungal conidia or hyphae of F. oxysporum f. sp. cubense were observed in the yellowing and wilted leaves. Surprisingly, we found that Foc 4 could spread beyond the rhizome, into the pseudostem and up to the leaves. It might be explained that sporulation and germination of secondary mycelium was crucial for rapid upward colonization (Beckman and Roberts
1995). By comparing the difference of expansion ranges between Foc 1 and Foc4, we conclude that the difference of the two races in invasiveness to extend further upward from the rhizomes to the upper parts of plants defines their difference in aggressiveness.

Another intriguing finding was that, when the pathogens expanded to the banana rhizome tissues, large amounts of starch granules were produced in the rhizome cells, and the starch contents were much higher after infection with Foc 1 than after infection with Foc4. Consistent with this observation, the expression of the key genes in the starch synthetic pathway was significantly upregulated, and the upregulation levels were much higher after infection with Foc 1 than after infection with Foc4. In other studies, it has been noted that a large amount of starch accumulation occurs in the stem tissues of diseased orange (Etxeberria et al. 2009), diseased citrus leaves (Schneider, 1968), and the protoplasts of the leaves of the symptomatic sweet orange (Kim et al. 2009) when these plants were infected with huanglongbing pathogens ('Candidatus Liberibacter spp.'). Moreover, average content of starch in the diseased citrus leaves was six times higher than that in the healthy citrus leaves (Takushi et al. 2007). However, little is known regarding the relationship between starch contents and the plant resistance. Our previous microscopic observation results indicated that Foc 1 spread slowly and was colonized less in the rhizomes, whereas Foc4 showed opposite results. Thus, we speculate that the amount of starch accumulation may be significantly related to the resistance levels of banana to two races of pathogens. Starch is an important energy source in plant cells and may be involved in the synthesis of many resistance-related physical and biochemical substances. Moreover, a substantial increase in the starch contents in the cells may increase the density of cellular tissues (Kuang et al. 2013), thereby directly slowing down the expansion rate of Foc 1 in the banana rhizome and root tissues. However, these hypotheses need to be confirmed in future studies.

Matsumoto et al. (1995) and Dong et al. (2012) suggested that FA could act as a virulence factor in Fusarium wilt of banana. Harborne et al. (1993) and Tan et al. (2011) indicated that FA played a direct role in pathogenesis, and the contents of FA in diseased plants is positively correlated with the virulence of $F$. oxysporum $\mathrm{f}$. sp. cubense. In the present study, we found that a certain concentration of FA could induce the same symptoms in the banana plants as the disease. Moreover, we observed that the contents of FA were significantly higher in the roots, rhizomes, and pseudostems after infection with Foc4 than after infection with Foc1. However, the amounts of FA produced by Foc 1 and Foc 4 in vitro culture were not
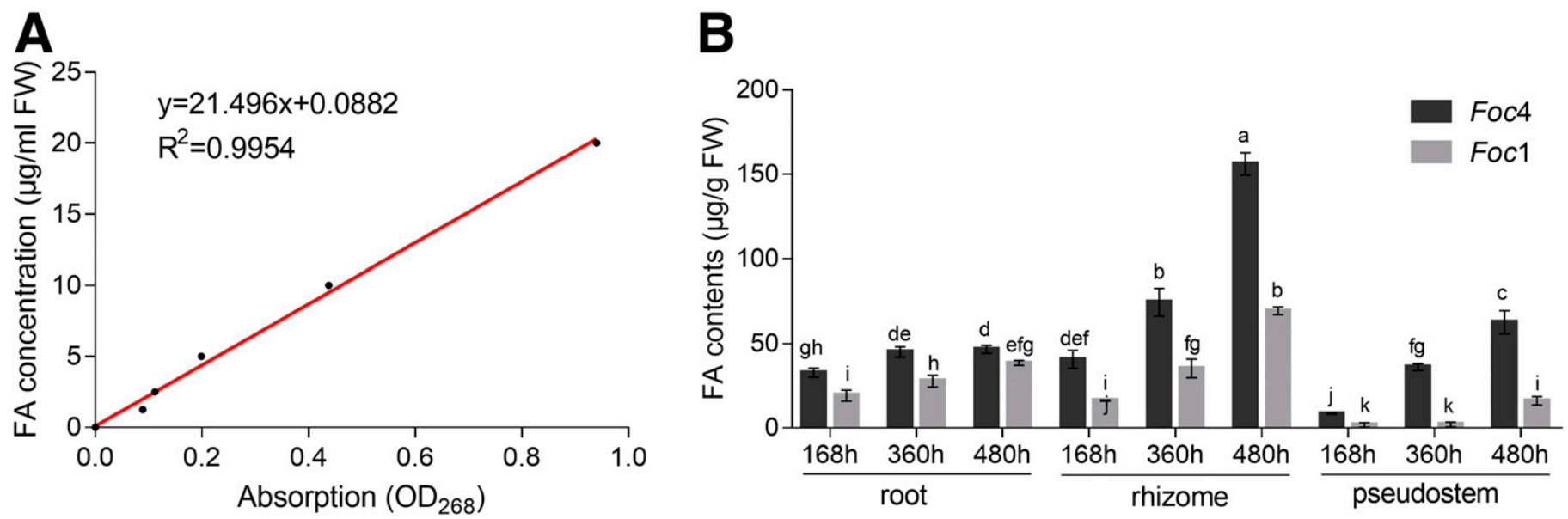

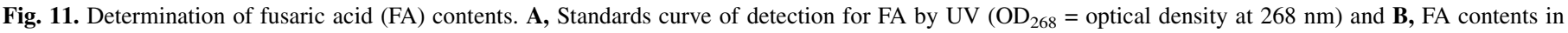

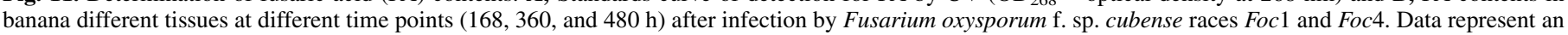

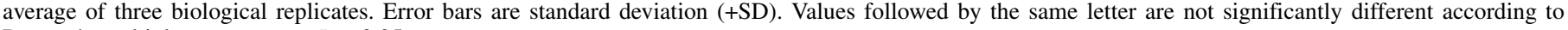
Duncan's multiple range test at $P<0.05$. 


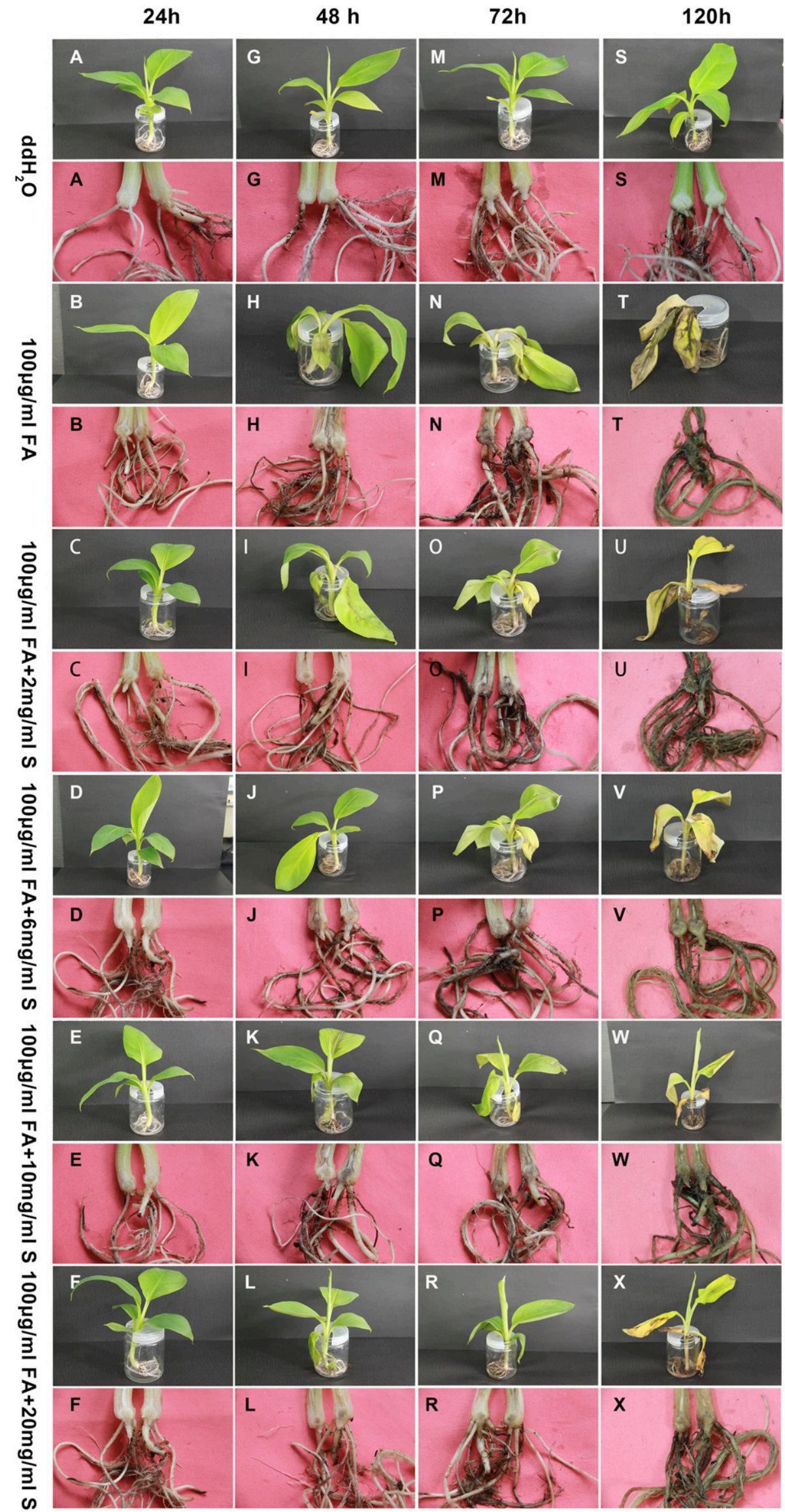

Fig. 12. Effects of different amounts of starch powder on phytotoxicity induced by fusaric acid (FA) at different time points (24, 48, 72 , and 96 h). A, G, M, and S, Treated with sterile water; B, H, N, and T, treated with FA at $100 \mu \mathrm{g} / \mathrm{ml} ; \mathbf{C}, \mathbf{I}, \mathbf{O}$, and $\mathbf{U}$, treated with FA at $100 \mu \mathrm{g} / \mathrm{ml}$ and starch powder at $2 \mathrm{mg} / \mathrm{ml}$; $\mathbf{D}, \mathbf{J}, \mathbf{P}$, and $\mathbf{V}$, treated with FA at $100 \mu \mathrm{g} / \mathrm{ml}$ and starch powder at $6 \mathrm{mg} / \mathrm{ml} ; \mathbf{E}, \mathbf{K}, \mathbf{Q}$, and $\mathbf{W}$, treated with FA at $100 \mu \mathrm{g} / \mathrm{ml}$ and starch powder at $10 \mathrm{mg} / \mathrm{ml}$; and $\mathbf{F}, \mathbf{L}, \mathbf{R}$, and $\mathbf{X}$, treated with FA at $100 \mu \mathrm{g} / \mathrm{ml}$ and starch powder at $20 \mathrm{mg} / \mathrm{ml}$. 
significantly different. This indicates that the amounts of FA production in banana plants between Foc 1 and Foc4 reflects the difference of virulence between the two F. oxysporum $\mathrm{f}$. sp. cubense races. High concentrations of FA in plants can lead to the destruction of the plant cell membrane (Bacon et al. 1996; D'Alton and Etherton 1984; López-Díaz et al. 2018; Ruiz et al. 2015) and cause plant tissues to lose water, resulting in plant withering (Dong et al. 2014). However, low concentrations of FA may induce the synthesis of phytoalexins and stimulate plant defense response signals (Bouizgarne et al. 2006). Consistent with the previous studies, our results showed that the lower amounts of FA in banana plants after Foc 1 infection could increase the expression level of defense-related genes (Fig. 13) and, ultimately, cause plants to exhibit resistance to Foc 1 , whereas the production of a large amount of FA in banana plants after Foc4 infection could destroy the cell membrane function of plant tissues and further weaken plant tissues to promote virulence of Foc4.

Because the starch contents in infected plant tissues might contribute to the difference in Brazilian resistance to Foc 1 and Foc4, we further conducted an evaluation assay of the starch effect on the phytotoxicity induced with FA. Our results showed that starch has an important inhibitory effect on the phytotoxicity induced by FA, thereby leading to more resistance to the pathogens in the banana plants with high amounts of starch accumulation than with low amounts of starch accumulation. Starch consists of $10 \%$ amylose and $70 \%$ amylopectin. The water-soluble
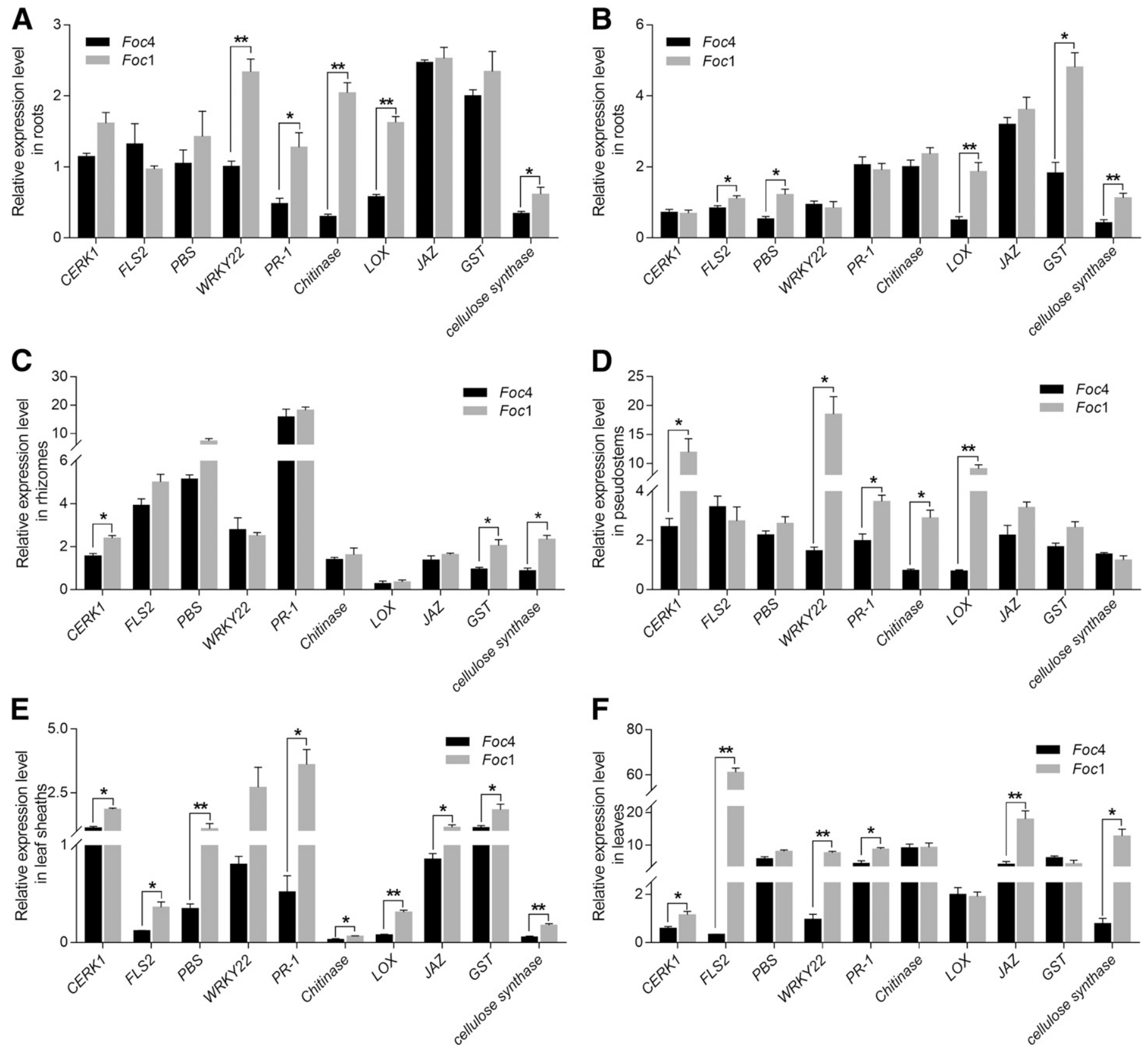

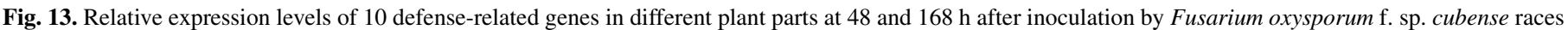

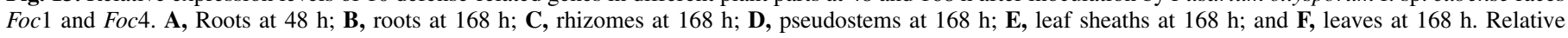

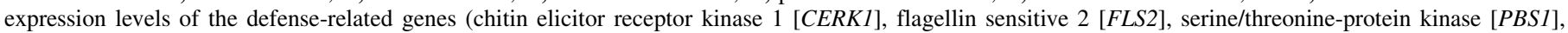

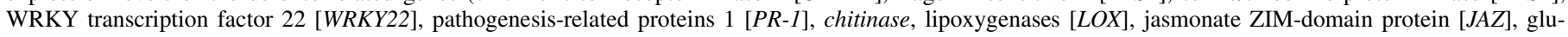

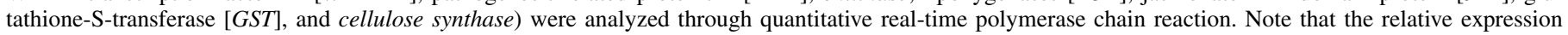

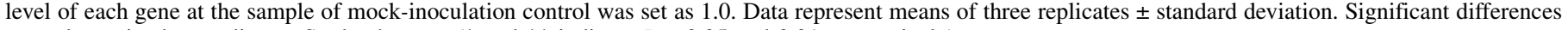
were determined according to Student's $t$ test (* and ** indicate $P<0.05$ and 0.01 , respectively). 
amylose is condensed by $\alpha$-glucose molecules to form long spirals, in which hydroxyl groups are still exposed to the helix for each glucose unit. Previous experimental reports showed that some small molecular compounds can interact with the hydroxyl group in glucose, so that the small molecular compounds can be embedded into the axis of the starch helix to form inclusion body complexes (Biais et al. 2006; Godet et al. 1993; Kong and Ziegler 2014; Kong et al. 2018). Therefore, we speculate that the effect of starch to counteract the activity of FA may be due to the formation of a complex of starch-FA, thus reducing the phytotoxicity of FA to banana plants. However, this specific mode of action requires further research.

\section{LITERATURE CITED}

Akila, R., Rajendran, L., Harish, S., Saveetha, K., Raguchander, T., and Samiyappan, R. 2011. Combined application of botanical formulations and biocontrol agents for the management of Fusarium oxysporum f. sp. cubense (Foc) causing Fusarium wilt in banana. Biol. Control 57:175-183.

Bacon, C. W., Porter, J. K., Norred, W. P., and Leslie, J. F. 1996. Production of fusaric acid by Fusarium species. Appl. Environ. Microbiol. 62:4039-4043.

Bai, T.-T., Xie, W.-B., Zhou, P.-P., Sun, J., Ruan, X.-L., and Li, H.-P. 2013. Transcriptome and expression profile analysis of highly resistant and susceptible banana roots challenged with Fusarium oxysporum f. sp. cubense tropical Race 4. PLoS One 8:e73945.

Beckman, C., Mace, M., Halmos, S., and McGahan, M. 1961. Physical barriers associated with resistance in Fusarium wilt of bananas. Phytopathology 51: 507-515.

Beckman, C. H., and Roberts, E. M. 1995. On the nature and genetic basis for resistance and tolerance to fungal wilt diseases of plants. Adv. Bot. Res. 21: 35-77.

Biais, B., Le Bail, P., and Robert, P. 2006. Structural and stoichiometric studies of complexes between aroma compounds and amylose. Polymorphic transitions and quantification in amorphous and crystalline areas. Carbohydr. Polym. 66:306-315.

Bouizgarne, B., El-Maarouf-Bouteau, H., Frankart, C., Reboutier, D., Madiona, K., Pennarun, A. M., Monestiez, M., Trouverie, J., Amiar, Z., Briand, J., Brault, M., Rona, J. P., Ouhdouch, Y., El Hadrami, I., and Bouteau, F. 2006. Early physiological responses of Arabidopsis thaliana cells to fusaric acid: Toxic and signalling effects. New Phytol. 169:209-218.

Chakrabarti, D. K., and Basu Chaudhary, K. C. 1980. Correlation between virulence and fusaric acid production in Fusarium oxysporum f. sp. carthami. J. Phytopathol. 99:43-46.

Chen, L., Zhong, H., Kuang, J., Li, J., Lu, W., and Chen, J. 2011. Validation of reference genes for RT-qPCR studies of gene expression in banana fruit under different experimental conditions. Planta 234:377-390.

Curir, P., Guglieri, L., Dolci, M., Capponi, A., and Aurino, G. 2000. Fusaric acid production by Fusarium Oxysporum f. sp. lilii and its role in the lily basal rot disease. Eur. J. Plant Pathol. 106:849-856.

D'Alton, A., and Etherton, B. 1984. Effects of fusaric acid on tomato root hair membrane potentials and ATP levels. Plant Physiol. 74:39-42.

Dita, M. A., Waalwijk, C., Buddenhagen, I. W., Souza, M. T., Jr., and Kema, G. H. J. 2010. A molecular diagnostic for tropical race4 of the banana Fusarium wilt pathogen. Plant Pathol. 59:348-357.

Dong, X., Ling, N., Wang, M., Shen, Q.-R., and Guo, S.-W. 2012. Fusaric acid is a crucial factor in the disturbance of leaf water imbalance in Fusariuminfected banana plants. Plant Physiol. Biochem. 60:171-179.

Dong, X., Xiong, Y., Ling, N., Shen, Q., and Guo, S. 2014. Fusaric acid accelerates the senescence of leaf in banana when infected by Fusarium. World J. Microbiol. Biotechnol. 30:1399-1408.

Etxeberria, E., Gonzalez, P., Achor, D., and Albrigo, G. 2009. Anatomical distribution of abnormally high levels of starch in HLB-affected Valencia orange trees. Physiol. Mol. Plant Pathol. 74:76-83.

Fan, H.-Y., Dong, H.-H., Xu, C.-X., Liu, J., Hu, B., Ye, J.-W., Mai, G.-W., and Li, H.-P. 2017. Pectin methylesterases contribute the pathogenic differences between races 1 and 4 of Fusarium oxysporum f. sp. cubense. Sci. Rep. 7: Article 13140.

Fraser-Smith, S., Czislowski, E., Meldrum, R. A., Zander, M., O'Neill, W., Balali, G. R., and Aitken, E. A. B. 2014. Sequence variation in the putative effector gene SIX8 facilitates molecular differentiation of Fusarium oxysporum f. sp. cubense. Plant Pathol. 63:1044-1052.

Freitag, M., Ciufetti, L., and Selker, E. 2001. Expression and visualization of green fluorescent protein (GFP) in Neurospora crassa. Fungal Genet. Newsl. 48:15-19.

Fu, L., Ryan Penton, C., Ruan, Y., Shen, Z., Xue, C., Li, R., and Shen, Q. 2017. Inducing the rhizosphere microbiome by biofertilizer application to suppress banana Fusarium wilt disease. Soil Biol. Biochem. 104:39-48.
Gapillout, I., Milat, M. L., and Blein, J. P. 1996. Effects of fusaric acid on cells from tomato cultivars resistant or susceptible to Fusarium oxysporum f. sp. lycopersici. Eur. J. Plant Pathol. 102:127-132.

Getha, K., and Vikineswary, S. 2002. Antagonistic effects of Streptomyces violaceusniger strain G10 on Fusarium oxysporum f. sp. cubense race 4: Indirect evidence for the role of antibiosis in the antagonistic process. J. Ind. Microbiol. Biotechnol. 28:303-310.

Godet, M. C., Buleon, A., and Tran, V. 1993. Structural features of fatty acidamylose complexes. Carbohydr. Polym. 21:91-95.

Guo, L.-J., Han, L.-J., Yang, L.-Y., Zeng, H.-C., Fan, D.-D., Zhu, Y.-B., Feng, Y., Wang, G.-F., Peng, C.-F., Jiang, X.-T., Zhou, D.-J., Ni, P.-X., Liang, C.-C., Liu, L., Wang, J., Mao, C., Fang, X.-D., Peng, M., and Huang, J.-S. 2014. Genome and transcriptome analysis of the fungal pathogen Fusarium oxysporum f. sp. cubense causing banana vascular wilt disease. PLoS One 9:e95543.

Guo, L.-J., Yang, L.-Y., Liang, C.-C., Wang, G.-F., Dai, Q.-D., and Huang, J.-S. 2015. Differential colonization patterns of bananas (Musa spp.) by physiological race 1 and race 4 isolates of Fusarium oxysporum f. sp. cubense. J. Phytopathol. 163:807-817.

Harborne, J. B., Baxter, H., and Moss, G. P. 1993. Phytochemical Dictionary. Taylor \& Francis, London, UK.

Hovenkamp-Hermelink, J. H. M., Jacobsen, E., Ponstein, A. S., Visser, R. G. F., Vos-Scheperkeuter, G. H., Bijmolt, E. W., de Vries, J. N., Witholt, B., and Feenstra, W. J. 1987. Isolation of an amylose-free starch mutant of the potato (Solanum tuberosum L.). Theor. Appl. Genet. 75:217-221.

Kim, J., Sagaram, U. S., Burns, J. K., Li, J., and Wang, N. 2009. Response of sweet orange (Citrus sinensis) to 'Candidatus Liberibacter asiaticus' Infection: Microscopy and microarray analyses. Phytopathology 99:50-57.

Kong, L., and Ziegler, G. R. 2014. Molecular encapsulation of ascorbyl palmitate in preformed V-type starch and amylose. Carbohydr. Polym. 111: 256-263.

Kong, L. Y., Yucel, U., Yoksan, R., Elias, R. J., and Ziegler, G. R. 2018. Characterization of amylose inclusion complexes using electron paramagnetic resonance spectroscopy. Food Hydrocolloids 82:82-88.

Kuang, R.-B., Li, C.-Y., Yang, J., Wei, Y.-R., Yang, Q.-S., Hu, C.-H., Sheng, O., and Yi, G.-J. 2013. Cell structure alteration of banana cultivars with different resistance to Fusarium oxysporum f. sp. cubense. Mol. Plant Breed. 11:193-198.

Li, B., Du, J., Lan, C., Liu, P., Weng, Q., and Chen, Q. 2013. Development of a loop-mediated isothermal amplification assay for rapid and sensitive detection of Fusarium oxysporum f. sp. cubense race 4. Eur. J. Plant Pathol. 135:903-911.

Li, C.-Q., Shao, J.-F., Wang, Y.-J., Li, W.-B., Guo, D.-J., Yan, B., Xia, Y., and Peng, M. 2013. Analysis of banana transcriptome and global gene expression profiles in banana roots in response to infection by race 1 and tropical race 4 of Fusarium oxysporum f. sp. cubense. BMC Genomics 14:851.

Li, C.-Q., Yang, J.-H., Li, W.-B., Sun, J.-B., and Peng, M. 2017. Direct root penetration and rhizome vascular colonization by Fusarium oxysporum $\mathrm{f}$. sp. cubense are the key steps in the successful infection of Cavendish cv. Brazil. Plant Dis. 101:2073-2078.

Li, C.-Y., Chen, S., Zuo, C.-W., Sun, Q.-M., Ye, Q., Yi, G.-J., and Huang, B.-Z. 2011. The use of GFP-transformed isolates to study infection of banana with Fusarium oxysporum f. sp. cubense race 4. Eur. J. Plant Pathol. 131: 327-340.

Li, C.-Y., Deng, G.-M., Yang, J., Altus, V., Yan, J., Kuang, R.-B., Zuo, C.-W., Lv, Z.-C., Yang, Q.-S., Sheng, O., Wei, Y.-R., Hu, C.-H., Dong, T., and Yi, G.-J. 2012. Transcriptome profiling of resistant and susceptible Cavendish banana roots following inoculation with Fusarium oxysporum f. sp. cubense tropical race 4. BMC Genomics 13:374.

Li, M.-H., Xi, P.-G., Ding, Z.-J., and Qi, P.-K. 2007. Race Identification of Fusarium oxysporum f. sp. cubense, the causal agent of banana Fusarium wilt in Guangdong province. Hua Nan Nong Ye Da Xue Xue Bao 28:38-41.

Li, M.-H., Yu, X.-T, Wang, H.-F., Zhou, J.-N, Xi, P.-G., and Jiang, Z.-D. 2012. Rapid detection and identification of Fusarium oxysporum f. sp. cubense race 1 and race 4. Sci. Agric. Sin. 45:3971-3979.

Li, W. M., Dita, M., Wu, W., Hu, G. B., Xie, J. H., and Ge, X. J. 2015. Resistance sources to Fusarium oxysporum f. sp. cubense tropical race 4 in banana wild relatives. Plant Pathol. 64:1061-1067.

Lin, Y.-H., Chang, J.-Y., Liu, E.-T., Chao, C.-P., Huang, J.-W., and Chang, P.-F. L. 2009. Development of a molecular marker for specific detection of Fusarium oxysporum f. sp. cubense race 4. Eur. J. Plant Pathol. 123: 353-365.

López-Díaz, C., Rahjoo, V., Sulyok, M., Ghionna, V., Martin-Vicente, A., Capilla, J., Di Pietro, A., and López-Berges, M. S. 2018. Fusaric acid contributes to virulence of Fusarium oxysporum on plant and mammalian hosts. Mol. Plant Pathol. 19:440-453.

Lorang, J. M., Tuori, R. P., Martinez, J. P., Sawyer, T. L., and Redman, R. S. 2001. Green fluorescent protein is lighting up fungal biology. Appl. Environ. Microbiol. 67:1987-1994. 
Ma, L., Shuang, J., Lin, G.-M., Cai, J.-H., Ye, X. X., Chen, H.-B., Li, M.-H., Li, H.-P., Tomáš, T., Jozef, S., and Xu, C.-X. 2013. Wound-induced pectin methylesterases enhance banana (Musa spp. AAA) susceptibility to Fusarium oxysporum f. sp. cubense. J. Exp. Bot. 64:2219-2229.

Matsumoto, K., Barbosa, M. L., Souza, L. A. C., and Teixeira, J.-B. 1995. Race 1 Fusarium wilt tolerance on banana plants selected by fusaric acid. Euphytica 84:67-71.

Michielse, C. B., and Rep, M. 2009. Pathogen profile update: Fusarium oxysporum. Mol. Plant Pathol. 10:311-324.

Morpurgo, R., Lopato, S. V., Afza, R., and Novak, F. J. 1994. Selection parameters for resistance to Fusarium oxysporum f. sp. cubense race 1 and race 4 on diploid banana (Musa acuminata Colla). Euphytica 75:121-129.

Mullins, E. D., Chen, X., Romaine, P., Raina, R., Geiser, D. M., and Kang, S. 2001. Agrobacterium-mediated transformation of Fusarium oxysporum: An efficient tool for insertional mutagenesis and gene transfer. Phytopathology 91:173-180.

Naik, P. R., Sahoo, N., Goswami, D., Ayyadurai, N., and Sakthivel, N. 2008. Genetic and functional diversity among fluorescent pseudomonads isolated from the rhizosphere of banana. Microb. Ecol. 56:492-504.

Nel, B., Steinberg, C., Labuschagne, N., and Viljoen, A. 2006. The potential of nonpathogenic Fusarium oxysporum and other biological control organisms for suppressing Fusarium wilt of banana. Mol. Plant Pathol. 55: 217-223.

Niehaus, E.-M., von Bargen, K. W., Espino, J. J., Pfannmüller, A., Humpf, H.-U., and Tudzynski, B. 2014. Characterization of the fusaric acid gene cluster in Fusarium fujikuroi. Appl. Microbiol. Biotechnol. 98:1749-1762.

O’Donnell, K., Kistler, H. C., Cigelnik, E., and Ploetz, R. C. 1998. Multiple evolutionary origins of the fungus causing Panama disease of banana: Concordant evidence from nuclear and mitochondrial gene genealogies. Proc. Natl. Acad. Sci. U.S.A. 95:2044-2049.

Peng, J., Zhang, H., Chen, F.-P., Zhang, X., Xie, Y.-X., Hou, X.-W., Li, U.-Y., and Pu, J.-J. 2014. Rapid and quantitative detection of Fusarium oxysporum f. sp. cubense race 4 in soil by real-time fluorescence loop-mediated isothermal amplification. J. Appl. Microbiol. 117:1740-1749.

Peraza-Echeverria, S., Dale, J. L., Harding, R. M., Smith, M. K., and Collet, C. 2008. Characterization of disease resistance gene candidates of the nucleotide binding site (NBS) type from banana and correlation of a transcriptional polymorphism with resistance to Fusarium oxysporum f. sp. cubense race 4. Mol. Breed. 22:565-579.

Ploetz, R. C. 1994. Compendium of Tropical Fruit Diseases. The American Phytopathological Society, St. Paul, MN, U.S.A.

Ploetz, R. C. 2006. Fusarium wilt of banana is caused by several pathogens referred to as Fusarium oxysporum f. sp. cubense. Phytopathology 96: 653-656.

Ploetz, R. C., Herbert, J., Sebasigari, K., Hernandez, J. H., Pegg, K. G., Ventura, J., and Mayato, L. S. 1990. Importance of Fusarium wilt in different banana-growing regions. Pages 9-26 in: Fusarium Wilt of Banana. R. C. Ploetz, ed. American Phytopathological Society, St. Paul, MN, U.S.A.
Ruiz, J. A., Bernar, E. M., and Jung, K. 2015. Production of siderophores increases resistance to fusaric acid in Pseudomonas protegens. PLoS One 10:e0117040.

Schneider, H. 1968. Anatomy of greening-diseased sweet orange shoots. Phytopathology 58:1155-1160.

Stipanovic, R. D., Puckhaber, L. S., Liu, J., and Bell, A. A. 2011. Phytotoxicity of fusaric acid and analogs to cotton. Toxicon 57:176-178.

Stover, R. H. 1962. Fusarial wilt (Panama Disease) of bananas and other Musa species. Commonwealth Mycological Institute, Surrey.

Stover, R. H., and Malo, S. E. 1972. The occurrence of fusarial wilt in normally resistant 'Dwarf Cavendish' banana. Plant Dis. Rep. 56:1000-1003.

Sutherland, R., Viljoen, A., Myburg, A. A., and van den Berg, N. 2013. Pathogenicity associated genes in Fusarium oxysporum f. sp. cubense race 4. S. Afr. J. Sci. 109:1-10.

Takushi, T., Toyozato, T., Kawano, S., Taba, K., Taba, A., Ooshiro, M., Numazawa, M., and Tokeshi, M. 2007. Scratch method for simple, rapid diagnosis of citrus huanglongbing using iodine to detect high accumulation of starch in the citrus leaves. Jpn. J. Phytopathol. 73:3-8.

Tan, D. C., Flematti, G. R., Ghisalberti, E. L., Sivasithamparam, K., Chakraborty, S., Obanor, F., and Barbetti, M. J. 2011. Mycotoxins produced by Fusarium species associated with annual legume pastures and 'sheep feed refusal disorders' in Western Australia. Mycotoxin Res. 27:123-135.

Van Den Berg, N., Dave, K. B., Hein, I., Birch, P. R. J., Wingfield, M. J., and Viljoen, A. 2007. Tolerance in banana to Fusarium wilt is associated with early up-regulation of cell wall-strengthening genes in the roots. Mol. Plant Pathol. 8:333-341.

Visser, M., Gordon, T. R., Wingfield, B. D., Wingfield, M. J., and Viljoen, A. 2004. Transformation of Fusarium oxysporum f. sp. cubense, causal agent of Fusarium wilt of banana, with the green fluorescent protein (GFP) gene. Australas. Plant Pathol. 33:69-75.

Waite, B. H. 1977. Inoculation studies and natural infection of banana varieties with races 1 and 2 of Fusarium oxysporum f. cubense. Plant Dis. Rep. 61:15-19.

Wardlaw, C. W. 1931. The biology of banana wilt (Panama Disease). III. An examination of sucker infection through root-bases. Ann. Bot. (Lond.) os45:381-399.

Xiao, R.-F., Zhu, Y.-J., Li, Y.-D., and Liu, B. 2013. Studies on vascular infection of Fusarium oxysporum f. sp. cubense race 4 in banana by field survey and green fluorescent protein reporter. J. Plant Pathol. 2:44-51.

Zacky, F. A., and Ting, A. S. Y. 2015. Biocontrol of Fusarium oxysporum f. sp. cubense tropical race 4 by formulated cells and cell-free extracts of Streptomyces griseus in sterile soil environment. Biocontrol Sci. Technol. 25:685-696.

Zhang, X., Zhang, H., Pu, J.-J., Qi, Y.-X., Yu, Q.-F., Xie, Y.-X., and Peng, J. 2013. Development of a real-time fluorescence loop-mediated isothermal amplification assay for rapid and quantitative detection of Fusarium oxysporum f. sp. cubense tropical race 4 in soil. PLoS One 8:e82841.

Zhao, Y., Liu, W., Xu, Y.-P., Cao, J.-Y., Braam, J., and Cai, X.-Z. 2013. Genome-wide identification and functional analyses of calmodulin genes in Solanaceous specie. BMC Plant Biol. 13:70. 